\title{
REMOTE MAINTENANCE DESIGN GUIDE FOR COMPACT PROCESSING UNITS
}

\author{
John V. Draper and Reid L. Kress \\ Oak Ridge National Laboratory \\ Robotics and Process Systems Division \\ P. O. Box 2008 Oak Ridge, Tennessee 37831-6304 \\ Tel: $865-574-5478$ \\ Tel: 865-574-2468 \\ Barry L. Burks \\ The Providence Group, Inc. \\ 10330 Technology Drive \\ Knoxville, TN 37932 \\ Tel: $865-671-1434$
}

Date Published: August 2000

\author{
Prepared by \\ OAK RIDGE NATIONAL LABORATORY \\ Oak Ridge, Tennessee 37831 \\ managed by \\ UT-Battelle, LLC, \\ for the \\ U.S. Department of Energy \\ under contract DE-AC05-00OR22725
}




\section{CONTENTS}

1. INTRODUCTION.................................................................................................................................................

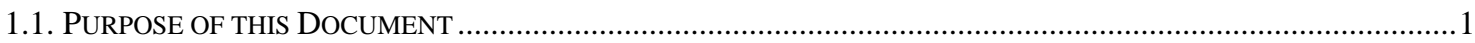



2. REFERENCE REMOTE HANDLING CONCEPT ...........................................................................................

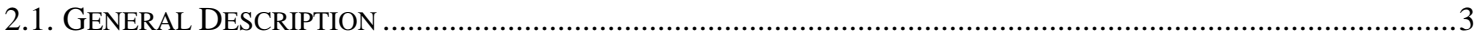

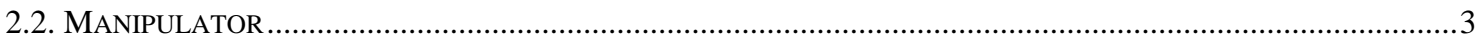

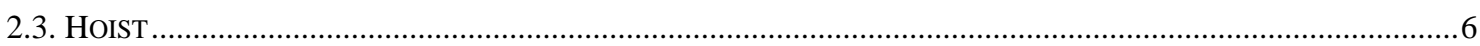

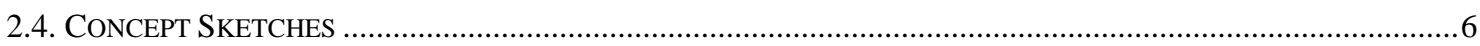

3. GENERAL GUIDELINES...............................................................................................................................9

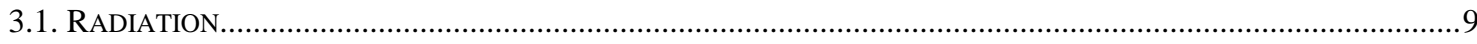

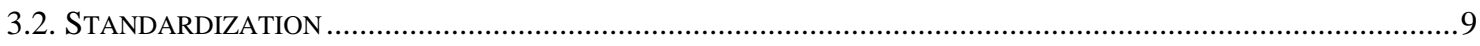



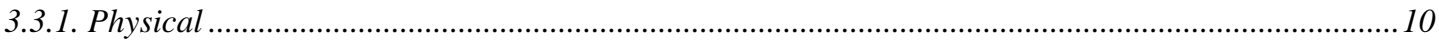

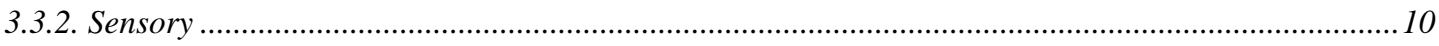

3.4. MODULARITY

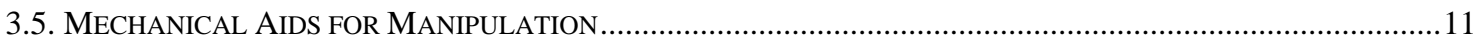

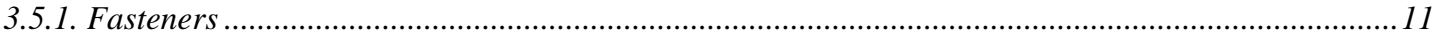

3.5.2. Fixtures

3.5.3. Guides

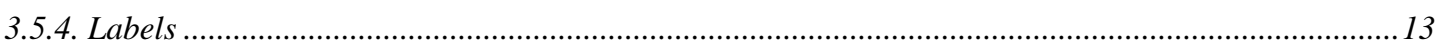




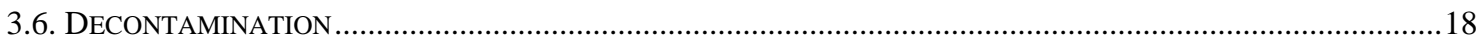

3.7. FAILURE CONSIDERATIONS AND MALFUNCTION DIAGNOSIS ................................................18

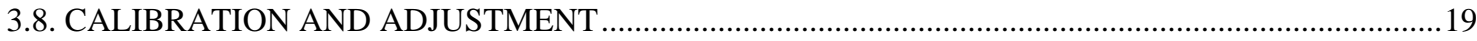

4. HUMAN-MACHINE INTERFACES ..............................................................................................................21

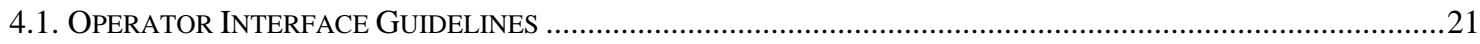

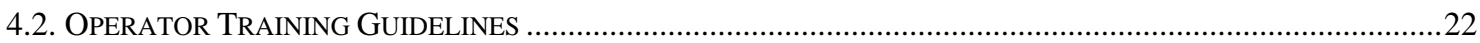

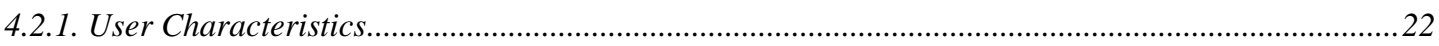

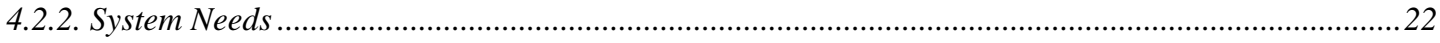

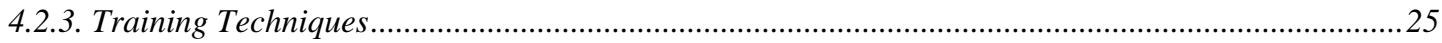

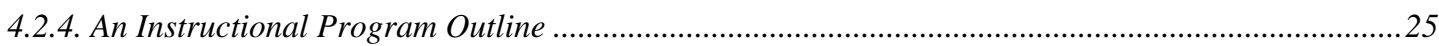



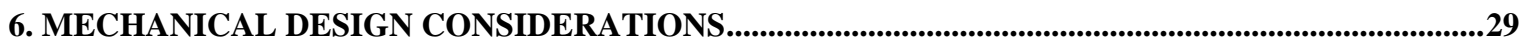

7. ELECTRONICS: CABLES, AND ELECTRICAL CONNECTORS...........................................................32

7.1. CABLES

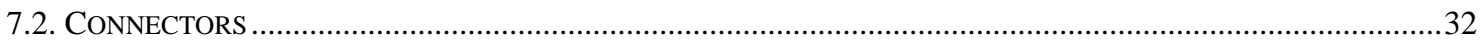

8. REMOTE MAINTENANCE AND SUPPORT EQUIPMENT ........................................................................35

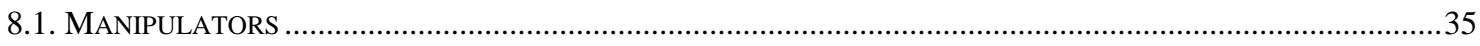

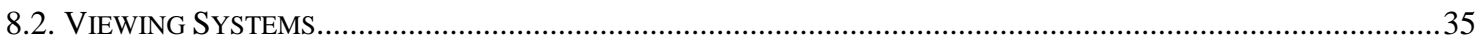

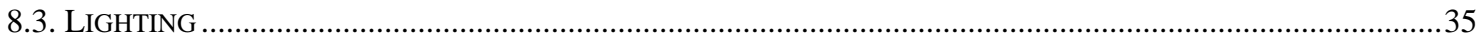

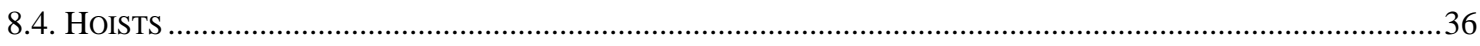



iii 
9. REMOTELY MAINTAINABLE FLUID CONNECTORS..........................................................................37

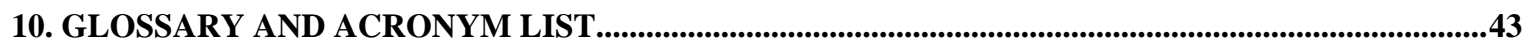

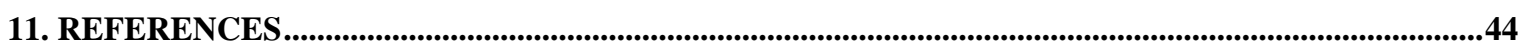




\section{LIST OF FIGURES}

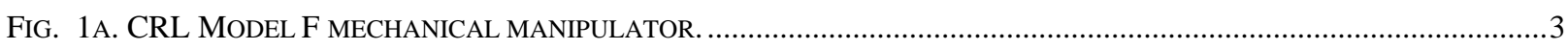

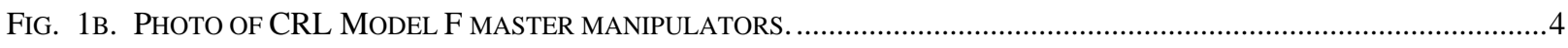



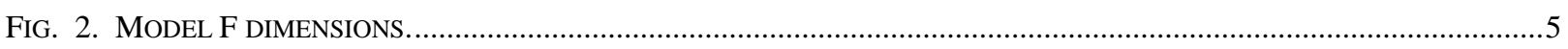

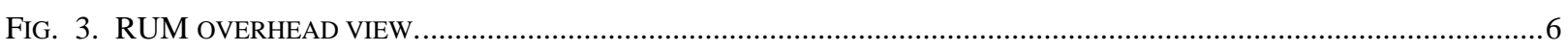

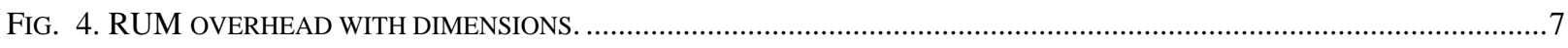

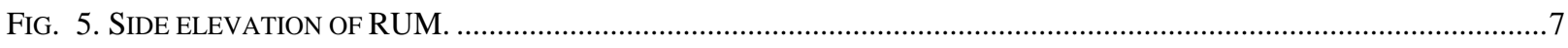

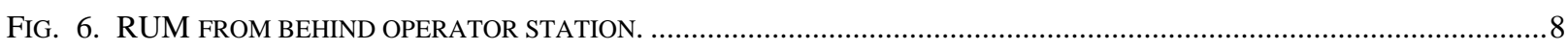

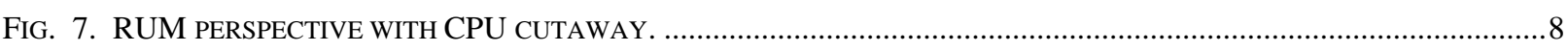

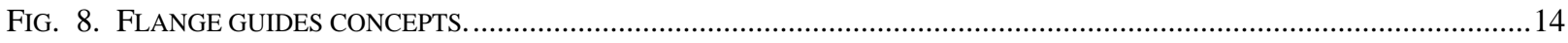

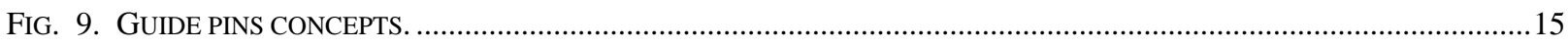

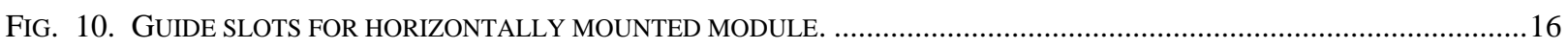

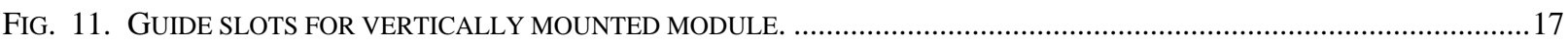

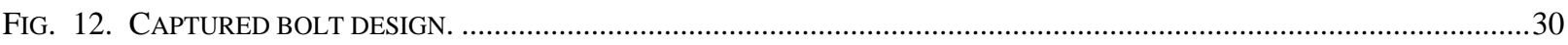

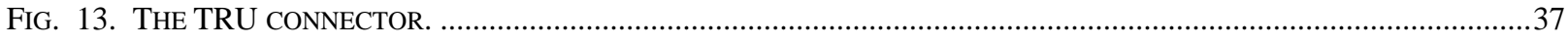



FIG. 15. TWO EXAMPLES OF TRU CONNECTORS FOR STRAIGHT THROUGH PIPE CONNECTIONS. NOTE THE CONICAL HEAD



Fig. 16. ANOTHER VIEW OF THE TRU CONNECTORS. THE ONE ON THE LEFT IS THE DOUBLE-CAM TYPE AND THE ONE ON

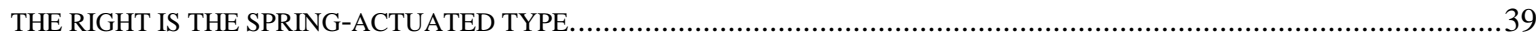

FIG. 17. HANFORD-PUREX CONNECTOR FOR RIGHT-ANGLE PIPE CONNECTIONS. ..................................................40

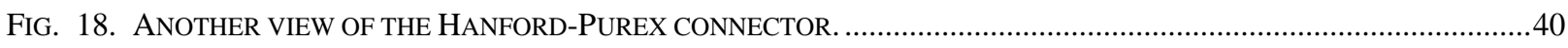

Fig. 19. A TRU CONNECTOR WITH A PIPE. NOTE THE FLAT GRIP HANDLE ON THE PIPE FOR EASIER REMOVAL WITH A 
PARALLEL-JAW TYPE GRIPPER. ALSO NOTE THE LIFTING BALE ON THE CONNECTOR BASE PLATE. .......

FIG. 20. SEVERAL TRU CONNECTORS WITH A MIXING/SPLITTING LINE. NOTE THE GRIP HANDLE ON THE PIPE. .41 


\section{LIST OF TABLES}

Table 1. Conservative estimates of shielding requiring lowering of dose rates to one-tenth of the

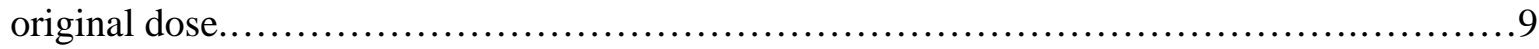

Table 2. Psychomotor abilities and importance to remote operations..........................23

Table 3. Cognitive abilities and their respective importance for RoboCon (from [6]).............24

Table 4. Partial task list with skill requirements.........................................24

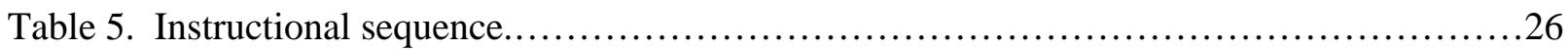




\begin{abstract}
Oak Ridge National Laboratory (ORNL) Robotics and Process Systems (RPSD) personnel have extensive experience working with remotely operated and maintained systems. These systems require expert knowledge in teleoperation, human factors, telerobotics, and other robotic devices so that remote equipment may be manipulated, operated, serviced, surveyed, and moved about in a hazardous environment. The RPSD staff has a wealth of experience in this area, including knowledge in the broad topics of human factors, modular electronics, modular mechanical systems, hardware design, and specialized tooling. Examples of projects that illustrate and highlight RPSD's unique experience in remote systems design and application include the following: (1) design of a remote shear and remote dissolver systems in support of U.S. Department of Energy (DOE) fuel recycling research and nuclear power missions; (2) building remotely operated mobile systems for metrology and characterizing hazardous facilities in support of remote operations within those facilities; (3) construction of modular robotic arms, including the Laboratory Telerobotic Manipulator, which was designed for the National Aeronautics and Space Administration (NASA) and the Advanced ServoManipulator, which was designed for the DOE; (4) design of remotely operated laboratories, including chemical analysis and biochemical processing laboratories; (5) construction of remote systems for environmental clean up and characterization, including underwater, buried waste, underground storage tank (UST) and decontamination and dismantlement (D\&D) applications.

Remote maintenance has played a significant role in fuel reprocessing because of combined chemical and radiological contamination. Furthermore, remote maintenance is expected to play a strong role in future waste remediation. The compact processing units (CPUs) being designed for use in underground waste storage tank remediation are examples of improvements in systems processing radiological contamination. A CPU is a minimally sized operating assemblage of processing equipment that performs a specified function. This technical report details remote maintenance guidelines for a CPU system being built at ORNL to ensure that sludge sent to a waste repository is in the appropriate form for transport through the storage facility pipe lines. The CPU conditions the sludge by (a) reducing the size of particulates that do not meet piping system requirements and (b) preparing the sludge for transport. The CPU has filters, grinders, sensors, valves, and pipes that must be remotely maintained. In the near future, the Defense Waste Processing Facility (DWPF), at the Savannah River Site (SRS) is expected to use many CPUs with remote maintenance characteristics similar to those of the ORNL CPU. These guidelines will aid the designers of those systems especially when design encompasses the often-used approach of surveying commercially available hardware and making modifications appropriate for remote operations. This is a cost-effective approach for design of systems for remote maintenance and is the approach that will be used in design of CPU's and remote maintenance equipment.
\end{abstract}




\section{INTRODUCTION}

\subsection{PURPOSE OF THIS DOCUMENT}

This document provides guidance to designers of equipment that must be maintained by remote handling systems. It is specifically aimed towards the requirements of remote maintenance for compact processing units (CPUs), which were developed as part of the underground storage tank (UST) remediation projects.

\subsection{REMOTE MAINTENANCE PHILOSOPHY}

General guidelines can be established for designing equipment intended for remote handling and maintenance. Excellent examples are found in refs. 1-3. More detailed specific guidelines can be developed for remote systems that are to be used for particular hazardous environments including chemical, biological, radiological, explosive, etc. This report focuses on some general guidelines for equipment that is to be maintained remotely; however, many specific hardware examples will be taken from the perspective of a chemical processing system. General design guidelines for remotely maintainable equipment are the following:

- Understand the system that is to be used to maintain the remote equipment, including access requirements.

- Develop and use standardized, manageable modules.

- Include lifting and gripping fixtures on all modules.

- Incorporate alignment devices wherever possible.

- Use standardized and fixed or captured parts.

- Create external fixtures for holding and aligning parts.

- Provide supports for anchoring flexible parts (e.g., hoses, wires, and airlines).

Characteristics of the required remote handling tasks and the environment of the CPU's drive the remote maintenance philosophy. Important characteristics include:

- There is usually a relatively small workspace (CPU interior).

- Most tasks are relatively light and they require dexterity.

- There are occasional medium-lift (100-200 lbs) requirements.

- There is typically good accessibility to the CPU enclosure (wide spaces around the boxes; boxtop may be removed).

- Most CPUs are located outdoors; however, general-use CPU's could be located indoors.

- There is a requirement for secondary shielding for manipulator operators, but there are none for containment (assumes CPU will be decontaminated internally before maintenance operations). 
Therefore, a remote maintenance system designed for this application should have the following characteristics:

- Simple mounting system (e.g., rack-mounted) with little need for manipulator re-positioning within the workspace, and no need for re-positioning in the course of a single task.

- Light-duty, dexterous manipulator arms.

- Remote viewing and lighting.

- Hoist for lifting components heavier than manipulator capacity.

- All-weather operator station.

- Capability for re-positioning entire system by crane, vehicle, or manually before beginning maintenance tasks.

- Shielding between operators and CPU.

- Leveling capability for deployment on tank farm terrain.

Section 2 describes a remote handling concept that meets these requirements and which may serve as a reference for future designs. The concept features a light-duty, mechanical, master-slave manipulator (MSM) which is mounted on a rack. The rack also supports the hoist, video systems, and an integrated operator station.

Reference 2 divides equipment designed for remote maintenance into four categories: parts are a single item (e.g., bolt, nut); components are an assembly of parts (e.g., valve, motor); a subassembly is an independent unit; and an assembly is a major grouping of components and subassemblies. In addition, one might add the term module, which is an assembly or subassembly having a uniquely identifiable function and clearly defined remote interfaces. Equipment and systems that are to be maintained remotely are generally configured into subassemblies and assemblies made up of remote-maintainable modules. A subassembly might be built around a specific unit operation or a specific device. An assembly might be a set of related devices. A module is generally identified by evaluating the probability of the failure of specific components and the possibility of remote repair of these components using the particular remote maintenance system. For example, failure of the bearings in a motor is common. Repair of motor bearings is difficult in a shop and nearly impossible using a remote manipulator system, consequently, an entire motor might be defined as a replaceable module. The module concept often extends beyond this point. A set of motors embedded within a mechanical subassembly might be defined as a single module if the motors are difficult to remove or align. Any designer of a system that is targeted for remote maintenance must consider the failure probability of particular components. Once the "weak" components are identified, they must be carefully designed into a "module" that is capable of being lifted, positioned, and attached and detached by the remote maintenance system. These design features will certainly facilitate faster remote maintenance, and in many cases, they may actually enable more precise remote maintenance.

Another consideration is cost. Modules could be defined based on the combination of remote maintainability and cost benefit. If it will cost more to separate modules during maintenance than to remove the two combined, then the module should be redefined to include both modules. 


\section{REFERENCE REMOTE HANDLING CONCEPT}

\subsection{GENERAL DESCRIPTION}

The design guidelines that are presented in this document are predicated on deployment of a particular remote handling reference concept, which was designed to be (1) sufficiently dexterous for CPU remote handling tasks, (2) reliable, (3) mobile, and (4) economical. To meet those requirements, the Remote Utility Module (RUM) is based on a commercially available mechanical MSM, which is supported by remote television viewing and a remotely controlled hoist (for heavy lifting). The remote handling system could be mounted on a moveable base and frame that could be rolled, pushed, or hoisted into position adjacent to the CPU to be maintained.

\subsection{MANIPULATOR}

The manipulator at the heart of the RUM is the Central Research Laboratories Model F manipulator. The Model $\mathrm{F}$ is a through-the-wall mechanical manipulator with $100-\mathrm{lb}$ (45-kg) lifting capacity. It has a volumetric coverage of $660 \mathrm{ft}^{3}\left(19 \mathrm{~m}^{3}\right)$ at a mounting height of $120 \mathrm{in}$. (3,050 $\mathrm{mm}$ ). Figures 1a, 1b, and 1c are photographs of the Model F (without the mounting). Dimensions of the Model F are shown in Fig. 2.



Fig. 1a. CRL Model F mechanical manipulator. 


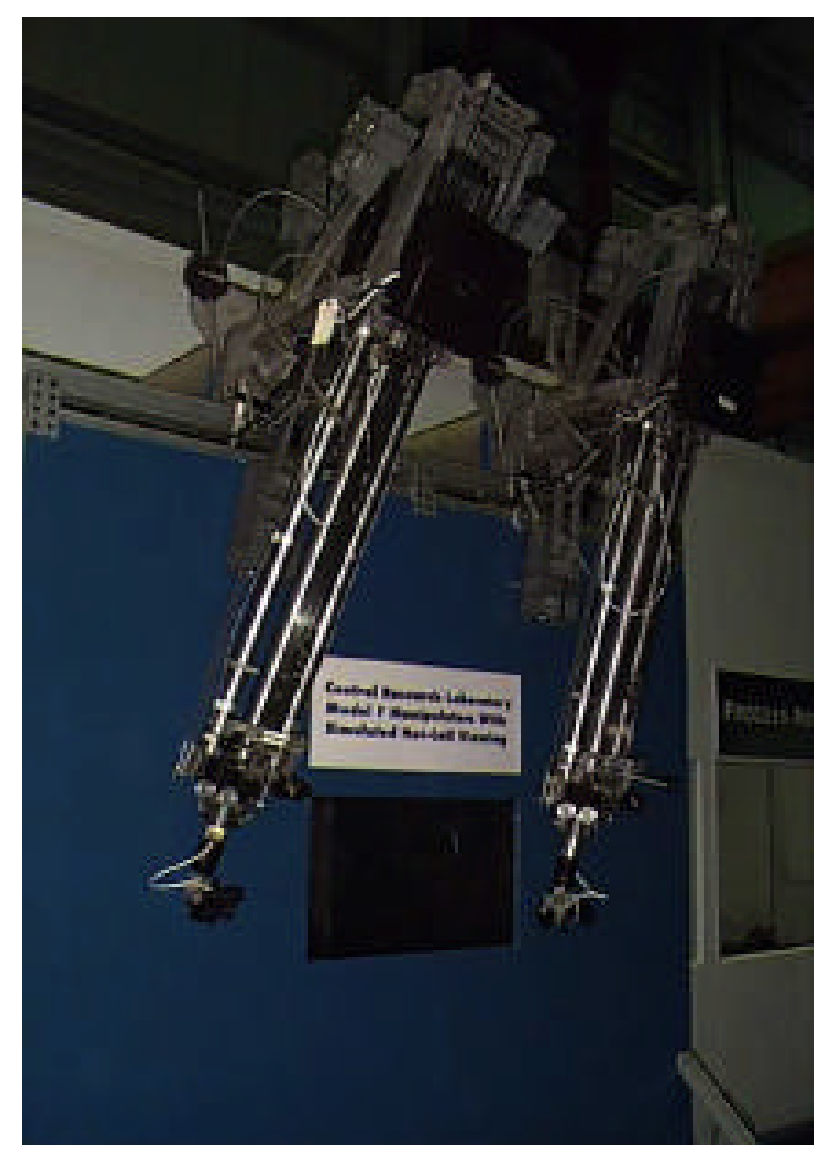

Fig. 1b. Photo of CRL Model F master manipulators.

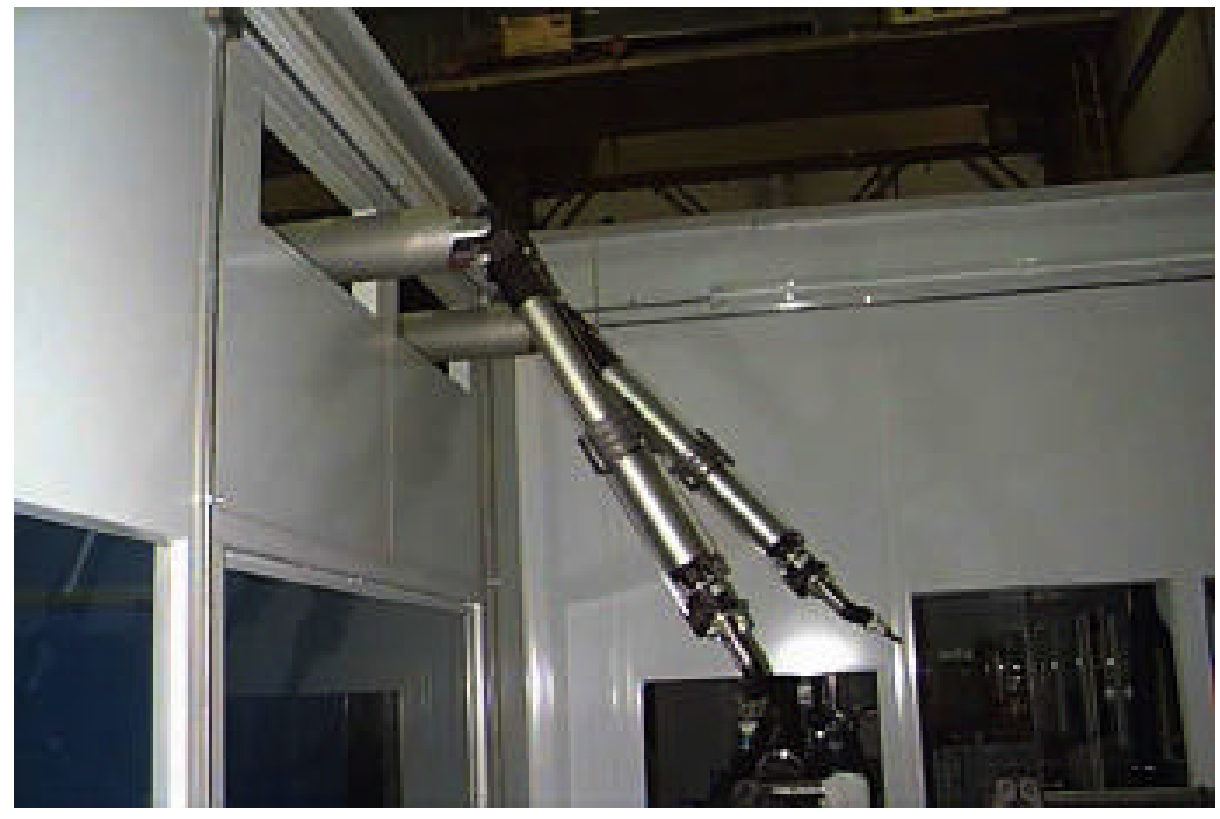

Fig. 1c. Photo of CRL Model F slave manipulators. 
For RUM, scaffolding rather than being inserted through a wall tube, as illustrated in Figure 2 will support the CRL Model-F. Furthermore, the user will be provided with television views of the remote area rather than having to view the area through a shielded window. Other than that, installation of the Model-F within RUM will be similar to that shown in Fig. 2.

\begin{tabular}{|c|c|c|c|}
\hline & $f-0-1$ & 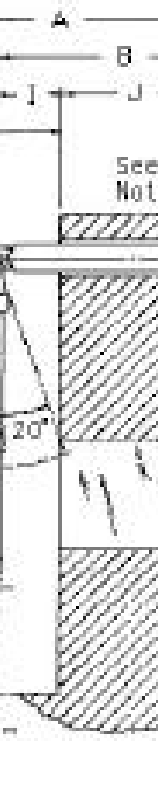 & $\frac{1}{4+4} \frac{1}{1259}$ \\
\hline \multicolumn{2}{|c|}{ Dimensions in inches } & Typical & Formula \\
\hline $\mathbf{A}$ & Removal clearance & 150.00 & $B+E+15$ \\
\hline $\mathrm{B}$ & Centerline distance & 78.00 & $\mathrm{I}+\mathrm{J}+\mathrm{K}$ \\
\hline $\mathrm{C}$ & $\begin{array}{l}\text { Minimum height clearance }(21 \\
\text { min.) }\end{array}$ & 24.33 & $0.5(\mathrm{~F})+7.7$ \\
\hline $\mathrm{D}$ & Master collapsed length & 57.00 & $1.25(\mathrm{Z})+8.25$ \\
\hline$E$ & Slave collapsed length & 57.00 & $1.25(\mathrm{Z})+8.25$ \\
\hline $\mathrm{F}$ & Extension & 33.25 & $0.8(\mathrm{E})-12.35$ \\
\hline $\mathrm{H}$ & Slave extended length & 129.25 & $\begin{array}{l}\{\mathrm{SQRT}[(\mathrm{R} * \mathrm{R})+(\mathrm{L} * \mathrm{~L})]\}- \\
6\end{array}$ \\
\hline $\mathrm{I}$ & Slave overhang $(8 \mathrm{~min})$. & 18.00 & \\
\hline $\mathrm{J}$ & Wall thickness & 36.00 & \\
\hline $\mathrm{K}$ & Master overhang (24 min.) & 24.00 & \\
\hline $\mathrm{L}$ & Operating height & 120.00 & \\
\hline $\mathrm{M}$ & Mounting height & 120.00 & \\
\hline $\mathrm{N}$ & Separation (40 min.) & 40.00 & \\
\hline $\mathrm{O}$ & Minimum cell depth & 53.50 & $E-3.5$ \\
\hline $\mathrm{R}$ & Tong tip radius at L & 62.39 & \\
\hline $\mathrm{Z}$ & "Z" Motion & 39.00 & $0.308(\mathrm{H})-0.8$ \\
\hline
\end{tabular}

Fig. 2. Model F dimensions. 
The Model F manipulator was selected to provide a dexterous handling capability with a weight-handling capability that is adequate for CPU maintenance tasks. However, the RUM rack is sufficiently generic such as for installation of other manipulator types.

\subsection{HOIST}

An auxiliary hoist is included in the RUM to provide a capability to lift components too heavy for the manipulators themselves to lift. The hoist will be located on the support structures between the slave arms. Hoists that can be operated from the handle at the hook may be useful for remote systems.

\subsection{CONCEPT SKETCHES}

Figure 3 shows the RUM concept from overhead, and Fig. 4 shows the overhead view with dimensions. Figure 5 shows the RUM in side elevation and Fig. 6 shows the view from behind the user station. Finally, Fig. 7 shows a perspective view of the RUM in position at the CPU.

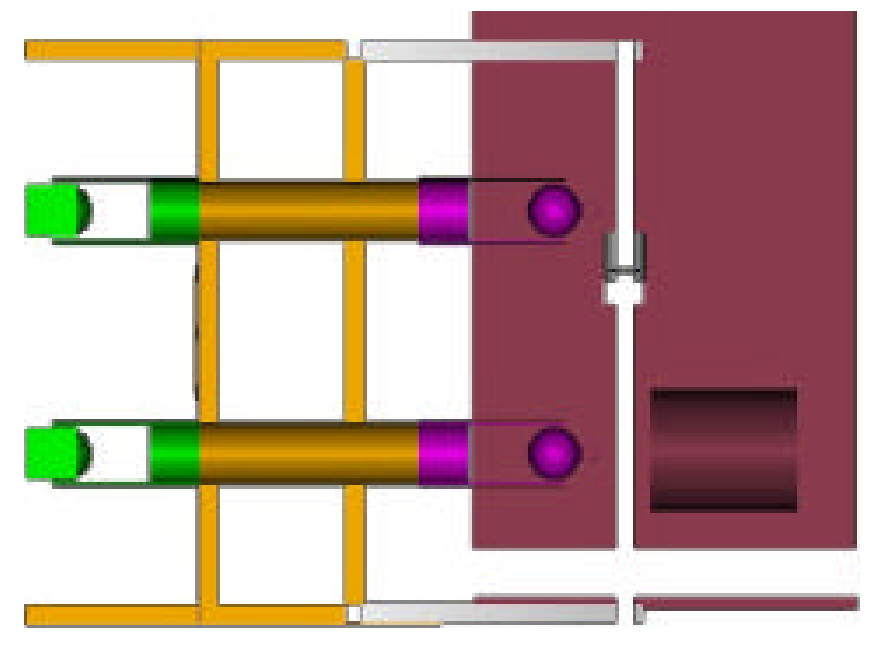

Fig. 3. RUM overhead view.

Provisions to ensure that loads greater than the rated loads are avoided will be provided. These include administrative controls and mechanical and electrical lift limiters. 


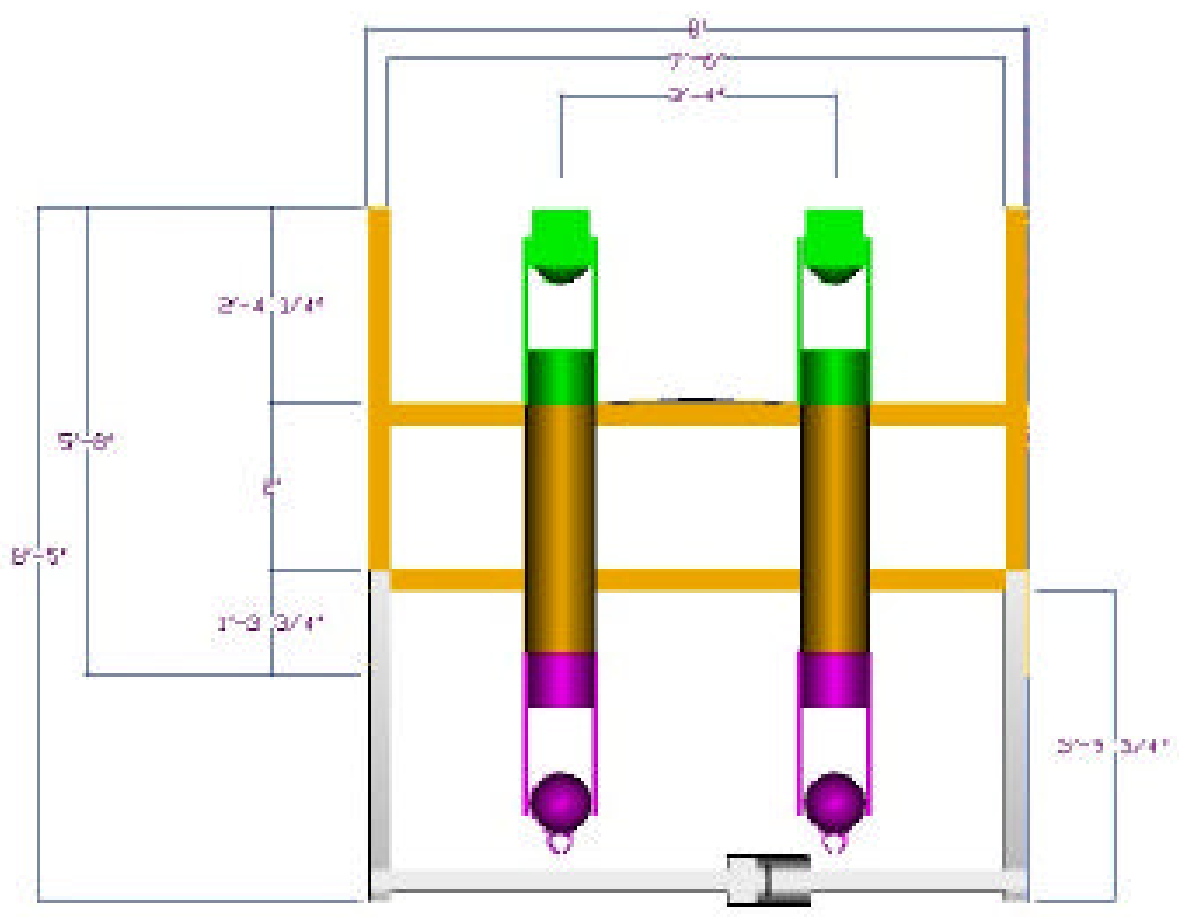

Fig. 4. RUM overhead with dimensions.



Fig. 5. Side elevation of RUM. 


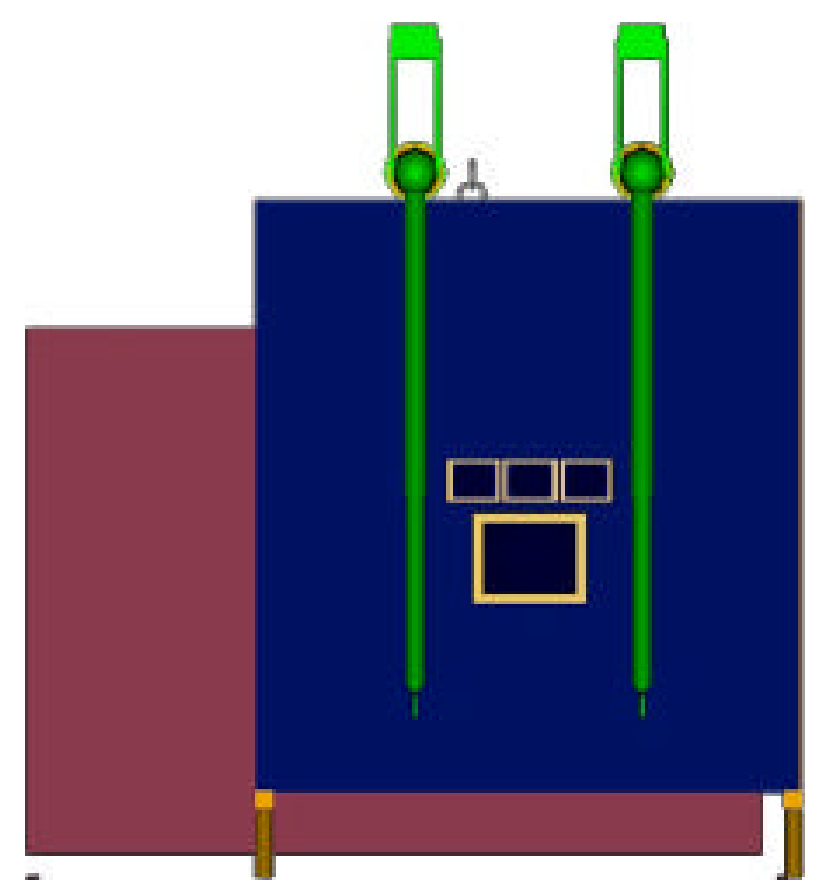

Fig. 6. RUM from behind operator station.

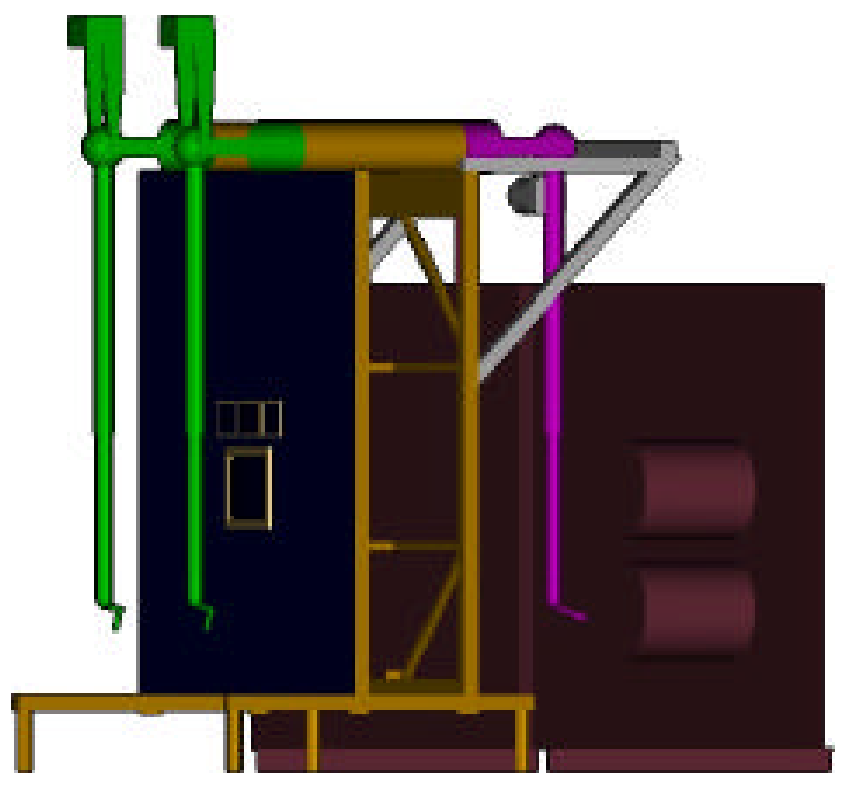

Fig. 7. RUM perspective with CPU cutaway. 


\section{GENERAL GUIDELINES}

\subsection{RADIATION}

Process systems that handle radioactive materials are usually required to be remotely maintainable to minimize exposure to personnel. To avoid frequent remote repair, components are frequently assembled of materials resistant to ionizing radiation. The characteristics of radioactivity are discussed in more detail in ref. 1.

The designer of radiochemical process plant equipment is chiefly concerned about the effects of gamma radiation on components and remote-maintenance system materials. Most metals are unaffected by gamma radiation. However, electronic components and organic materials such as elastomers, oils, and plastics may be severely affected and may have very limited use in areas of high-gamma intensity. Protection from radiation damage can be provided with local shielding when either the use of organics in the design is critical or alternative materials are unavailable. Weight, space, and cooling penalties usually result when shielding is used. Cooling is generally required in high fields. The amount of shielding required is a function of the radiation resistances of the design material, the radiation levels in the remote environment, and the location of the equipment in the remote environment. Table 1 lists shielding materials and thickness required reducing radiation dose rates to one-tenth of the unshielded value.

Table 1. Conservative estimates of shielding requiring lowering of dose rates to one-tenth of the original dose.

\begin{tabular}{lcccc}
\hline & \multicolumn{2}{c}{ Density } & \multicolumn{2}{c}{$\begin{array}{c}\text { One-tenth dose rate } \\
\text { thickness }\end{array}$} \\
\cline { 2 - 5 } Material & $\mathbf{g} / \mathbf{c m}^{\mathbf{3}}$ & $\mathbf{l b / i n .} \mathbf{3}^{\mathbf{3}}$ & $\mathbf{c m}$ & in. \\
\hline Concrete & 2.4 & 0.087 & 23.11 & 9.1 \\
Iron & 7.94 & 0.287 & 6.86 & 2.7 \\
Lead & 11.34 & 0.410 & 2.79 & 1.1 \\
Uranium & 18.76 & 0.678 & 1.37 & 0.54 \\
Tungsten & 19.64 & 0.710 & 1.78 & 0.7 \\
\hline
\end{tabular}

Of the commonly used materials, lead and tungsten make good gamma radiation shields for remote environments. Concrete and steel are common and can be cheaper. Concrete and water are most effective for neutron radiation.

\subsection{STANDARDIZATION}

Standard equipment selection reduces overall design and construction costs of a system, reduces spare parts inventories, minimizes operator-training time for maintenance, and decreases downtime. It also minimizes number and types of remote handling and fixtures. General standardization guidelines for equipment designers include the following: 
1. Commercially purchased components, modified if necessary, are preferred to specially designed and fabricated components.

2. Limit the number of different types of commercially purchased components.

3. Utilize standard design solutions, as described in this manual, wherever possible in preference to creating new design solutions.

\subsection{ACCESSIBILITY}

The designer of equipment that must be remotely maintained must ensure that there is adequate access to the process equipment. This access includes space for the maintenance system as well as auxiliary support systems such as vision and sensor systems.

\subsubsection{Physical}

There is a significant difference in the physical accessibility requirements for equipment to be repaired by force-reflecting servomanipulators rather than by hand. As an example, consider an impact wrench modified for remote-environment manipulator use. Typically overall dimensions are 41 to $46 \mathrm{~cm}$ (16 to $18 \mathrm{in}$.) long by 30 to $41 \mathrm{~cm}$ (12 to 16 in.) high by 15 to $20 \mathrm{~cm}$ (6 to 8 in.) wide. Use of this wrench to remove or loosen a bolt on an equipment module would not only require sufficient access space near the bolt but also a clear path of sufficient size such as to bring the tool into the work space from a direction accessible to the maintenance equipment. Other considerations include leaving sufficient clearance such as to accommodate thread travel as the bolt is loosened (allowing for positioning and travel before and during insertion) and ensuring that the bolt head and tool are visible with the remote-environment viewing equipment (often from multiple angles). Some general guidelines to ensure physical accessibility include the following.

1. Modules should be designed to be reached, disconnected, and handled by available remotehandling equipment, taking into consideration location in the cell and the relation of other modules and equipment.

2. Heavy modules should be accessible by an overhead bridge crane; moderately heavy modules should be accessible to any auxiliary hoist on the manipulator package, since manipulators and their associated hoist systems are limited in load capacity and reach.

3. Modules should be designed to be disconnected and removed with a minimum of disturbance to other equipment.

4. Modules must be designed to be transferred through available remote-environment transfer tunnels and penetrations.

\subsubsection{Sensory}

There is also a significant difference in the visual accessibility requirements for equipment to be repaired by force-reflecting servomanipulators rather than by hand. As in the example of the impact wrench in the previous section, ensuring that the bolt head and tool are visible with the remote-environment viewing equipment (often from multiple angles) is critical. Some general guidelines to ensure visual accessibility include the following. 
- Modules should be designed to ensure adequate viewing via shielded windows, a periscope, or closed-circuit television (CCTV) systems.

- $\quad$ The module equipment should be designed for ease of inspection and maintenance within the surrounding remote-environment space.

- $\quad$ Modules must be made so that they are easily discerned from background equipment.

- Module connections should be clearly identified and visible from multiple locations.

\subsection{MODULARITY}

Several sections in this report mention the importance of designing modules for remotely maintainable systems. Striving for a modular system design helps in a number of ways: (1) it helps ensure that a single design can be reused in different roles; (2) it reduces the spare parts inventory; (3) repair time is lessened, and remote repair is facilitated; (4) the system is easier to reconfigure by remote (or other) means; (5) overall system cost is reduced; (6) and training time and operation time are reduced for maintenance tasks. Modular design efforts should focus on module definition, interface definition, component packaging, and access and maintenance.

The following list contains some recommended design practices to provide for the replaceability of modules.

1. Design modules that can be remotely maintained using the available maintenance equipment and avoiding the need for special tools, jigs, and fixtures.

2. Provide as-built dimensions of all modules or replaceable components.

3. Mark and label modules to identify where they mate to the parent machine.

4. Mark and label all connecting cables, wires, process lines, etc.

5. Provide removal and replacement directions. Emphasize order of removal and connection of cables, wires, process lines, etc.

6. One should prescribe methods to stop flows or bypass process materials and to drain (and flush, if possible) components before their removal.

7. One should specify methods for removal and storage of process or product materials from the failed system.

8. One should assure that the design and associated maintenance time periods meet operating availability requirements.

9. One should recommend in-service preventive maintenance inspections and operations and methods for accomplishing them remotely.

\subsection{MECHANICAL AIDS FOR MANIPULATION}

\subsubsection{Fasteners}

Common fasteners for remotely maintained systems and equipment include bolts, nuts, screws, clamps, pins, and "limited-turn" connectors. The following set of guidelines for fasteners has been established to facilitate remote maintenance. 
1. Commercial fasteners are best from the standpoint of lowest cost and easy availability. Some modifications may need to be performed, for example, blunting the first few threads on a bolt for easy starting or modifying the handle on a pin to accommodate parallel-jaw grippers.

2. One should choose common sizes and attempt to keep a uniform size throughout the entire system. This uniformity will simplify tool selection and minimize the need for changing tools during maintenance operations.

3. The bolt and screw sizes need to be no smaller than $6 \mathrm{~mm}(0.25 \mathrm{in}$.) in diameter.

4. One should avoid slot-head, socket-head, torx-head, and other types of screws and bolts that require the insertion of a tool. Such insertions are difficult and it often requires small tools: also the slots, sockets, etc. can become clogged with dirt and other contamination.

5. One should choose coarse threads to reduce the possibility of cross threading.

6. One should deburr and clean all threads before they are introduced into the remote environment.

7. One should provide starting arrangements for screw fasteners by designating a slight chamfer or thread blunting on the screw end or a counterbore or countersink on the tapped hole. For example, commercial screws are often modified for remote maintenance applications by removing the first several threads. The underlying material is then chamfered and used as for remote alignment. This helps to prevent cross threading.

8. One should select ACME threads (ref. 4) in applications where frequent removal is anticipated.

9. Fastener metals require a minimum hardness of Rockwell C45 to resist damage from tools.

10. Bolts and nuts or screws and threaded seats of dissimilar materials or of dissimilar hardnesses resist galling.

11. Lubrication with radiation resistant lubricants may be required. Reference 1 has a comprehensive list of these lubricants.

12. One should design captured bolts on modules that are to be removed.

13. One should spring-load captured bolts to indicate disengagement and to prevent interference during module insertion. Spring-loading also helps prevent inadvertent engagement when other bolts are being tightened and also helps keep a tightened bolt in place.

14. One should install any screw fastener that is large enough to require an impact wrench for removal vertically or horizontally. Inclined installation will necessitate the motion of the impact wrench along a more difficult path, which is usually difficult for operators of telerobotic systems and mechanical master/slave systems.

15. When remotely inserting a threaded fastener that has not been modified for remote maintenance application, it is often useful to run in reverse until the threads are started, then run forward until tightened. If this process is automated, then the tightening torque (or current) could be monitored.

16. Magnetic properties of mating parts can be used advantageously during assembly.

17. Ball-lock pin fasteners work well; however, the gripping head must be modified to accommodate the manipulator system's gripping mechanism. In addition, the pins must be affixed to the module to avoid dropping them. Tag chains, tag cables, or a captured design are all acceptable methods of retention.

18. Toggle- and swing- type clamps are also viable alternatives. It will be necessary to provide spatial and visual access to the clamping-adjustment mechanism in the event that modifications are required.

19. One should consider using snap rings, roll pins, spring pins, cotter pins, spring clamps, and other spring-loaded, small fasteners only when absolutely necessary. These are frequently 
difficult for remote systems to handle and are easily dropped. These types of fasteners should be limited to out-of-cell, hands-on maintenance operations.

\subsubsection{Fixtures}

Fixtures can be used to help hold and align mating parts to facilitate remote assembly. They also can be used to align parts, align shafts, hold linkages in place, etc. during remote assembly and disassembly. If possible, it is best to attach fixtures to the base or the frame of the assembly rather than to the module. Fixtures that are designed to allow modules to "fall" or "rotate" into place incorporate an excellent feature. This design is especially effective when personnel must install motors and align the motors with shafts and couplings.

\subsubsection{Guides}

All remotely replaceable modules and assemblies require built-in alignment guides to simplify installation. General guidelines suggest:

- It is common practice to use two companion sets of guides to locate a module. The first set does gross positioning and leads the module into the second, higher precision guide set, which may be a set of close tolerance pins and holes to ensure a precise gear engagement, or a shaft-coupling engagement. A well chosen, two-stage guidance can lead a unit squarely in place using only a hoist, without requiring a manipulator system for alignment assistance.

- $\quad$ The design of a precision guide and locating procedure avoids undue tilt, binding, or seizing during installation and removal. Precise alignment of a module should occur over the last 3 to $5 \mathrm{~mm}$ (1/8 to $3 / 16$ in.) of vertical travel to avoid binding. Close-fitting guides made from metals dissimilar to the module case material can effectively reduce the occurrence of galling or binding.

- $\quad$ Alignment operations rely on in-cell television camera viewing. One should provide a clear view by the in-cell television cameras for proper module engagement and mating. Also one should avoid blocking the line-of-sight view of the guides with the module itself.

- Both gross and precision alignment guides may be comprised simply of one set of alignment pins, but they should be staggered in height to aid the engagement process.

- $\quad$ Some examples of alignment schemes for remote placement are shown in Figs. 8 through 11. Remotely replaceable modules should be installed and located by guides and pins in a manner such that the manipulator or crane hook can be detached before fasteners are engaged. The locating system is required to be accurate such as to ensure that the screws can then be engaged without damage to the screw threads or other fasteners.

\subsubsection{Labels}

All modules and components should be clearly marked for identification. Accountability of components and modules will be required for numerous purposes: including spare parts inventories and in-cell equipment identification, refurbishment, packaging, and disposal.

The modules are to be permanently labeled (i.e., stamped in stainless steel plates for protection from the cell environment). The labels or markings are to be placed in locations that are clearly visible to remote viewing cameras. More than one label may be required on a large module. 




Fig. 8. Flange guide concepts. 




Fig. 9. Guide pin concepts. 


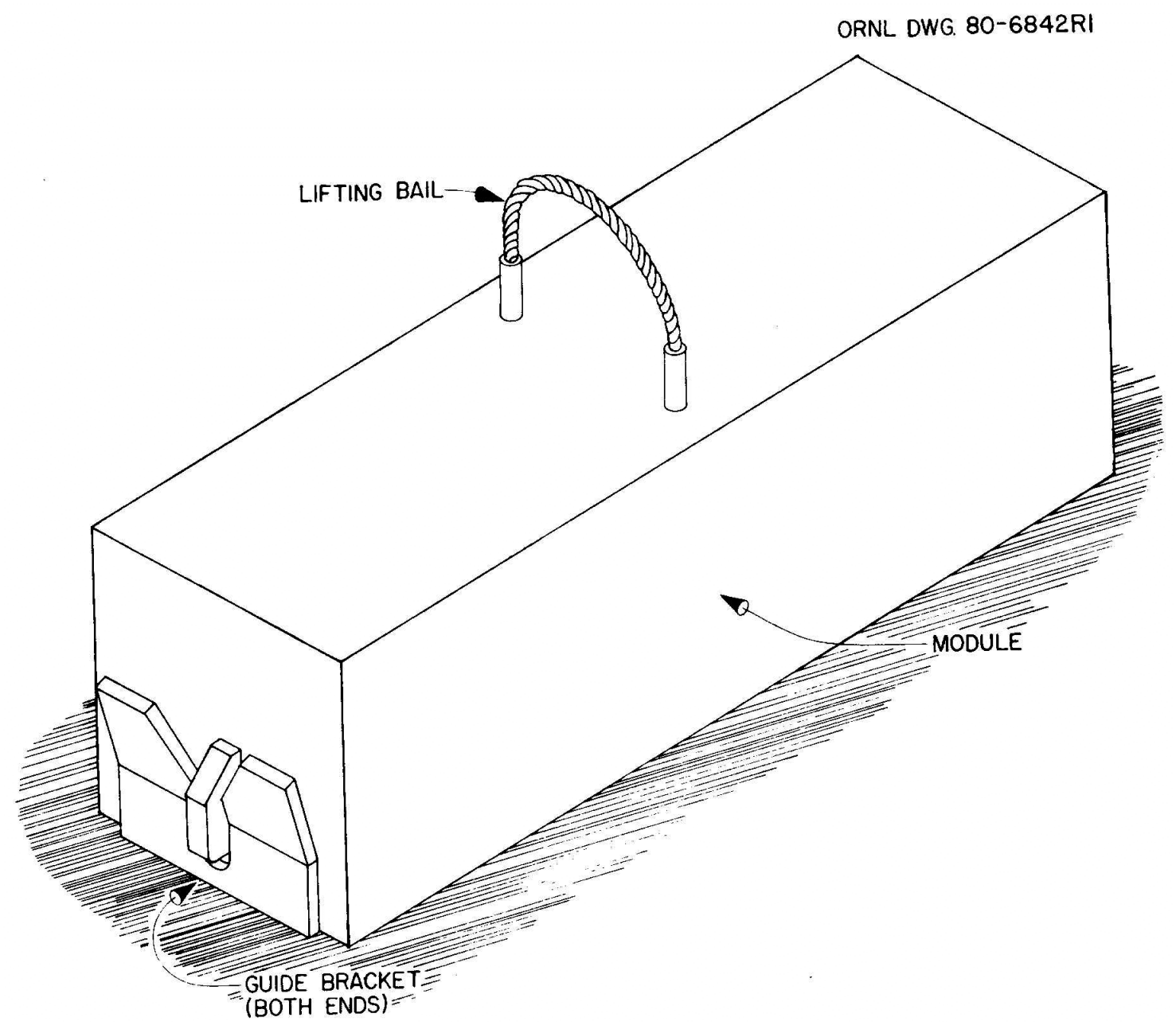

Fig. 10. Guide slot for horizontally mounted module. 


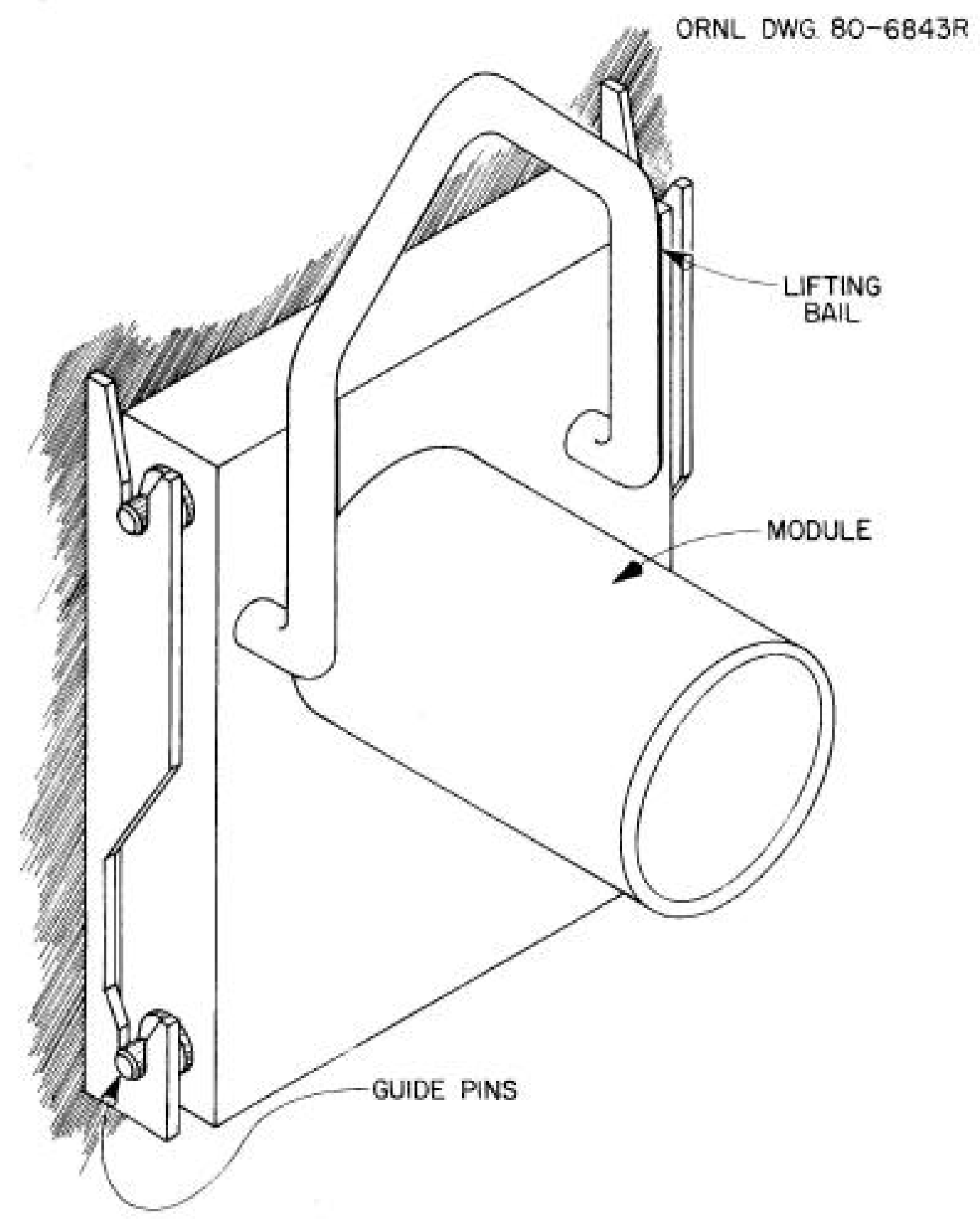

Fig. 11. Guide slot for vertically mounted module. 


\subsection{DECONTAMINATION}

Equipment taken outside the CPU must be decontaminated. Most equipment can be thoroughly decontaminated to reduce the gamma radiation at the surface to acceptable levels for contact maintenance or disposal preparations. The following considerations are important:

1. One should choose construction materials for equipment (scheduled to be decontaminated for contact maintenance and later reused) which resist degradation by the decontamination fluids and procedures.

2. Equipment, not to be reused, may be constructed of lower grade materials not necessarily resistant to the decontamination reagents.

3. One should consider the decontamination procedures so that the design of the equipment can reflect the following features:

- $\quad$ no blind holes unless provided with drain ports;

- $\quad$ specification of continuous welds to fill cracks and crevices;

- $\quad$ smooth or polished metal surfaces (electropolishing is a common finishing technique used widely in the nuclear industry);

- $\quad$ no porous materials, if possible; and

- $\quad$ no joints that may trap material, where possible.

4. The primary method of in-cell maintenance is the replacement of failed modules by remote handling and manipulation techniques. Subsequent repair of failed modules will, in many cases, require contact maintenance. There are three basic techniques to reduce ionizing radiation contamination to acceptable levels and permit contact maintenance on complex items such as television cameras and manipulator arms:

- Install gas tight and water tight shrouds that protect mechanisms and joints but do not impair operation. These can be placed around certain equipment before transferring the unit into the cell. The shrouds can prevent contamination from entering the joints and mechanisms and can be decontaminated effectively.

- If necessary place a shroud around the equipment before its transfer into the cell and remove the shroud before the item is transferred into the contact maintenance shop. This is commonly referred to as "booting."

- Decontaminate unshrouded equipment to acceptable levels. In this case, complete equipment rebuilding to replace items such as bearings and connectors, which are susceptible to damage by decontamination solutions, is usually required.

5. Equipment can be replaced in cells using "bag-out/bag-in" techniques, transfer locks, and heat sealable bags.

\subsection{FAILURE CONSIDERATIONS AND MALFUNCTION DIAGNOSIS}

The designer must anticipate unplanned events such as malfunctions and failures. When failures do occur, the resulting effects must be controlled to ensure safe shutdown and alleviate subsequent failures. Some general guidelines to ensure sensory accessibility are outlined below.

1. Modules and components should be placed so that ones that are most likely to fail are the easiest to access.

2. A method must be used to effectively detect failures and identify the specific malfunctions or failures and their respective causes. 
3. One should prescribe fail-safe conditions to recover from and repair all failures. (Note: This is normally done by operations team members, safety, facility and environmental representatives who performs a PPA (potential problem analysis) to define possible system failures and how to recover.

4. One should assure that the equipment meets the modular design criteria.

5. One should perform malfunction and failure analysis of key equipment, components, and operations to ensure that failures do not create subsequent failures.

\subsection{CALIBRATION AND ADJUSTMENT}

The calibration and adjustment of instruments and components by remote manipulation and viewing are difficult tasks. Remote-environment sensors, which are used to measure position, speed, acceleration force, temperature, pressure and flow present special problems. These components are subject to failure from use, from radiation, from corrosion effects, and from damage during remote operations. Some general guidelines in this area include the following.

1. Designers should minimize remote-environment use of calibration and adjustment mechanisms wherever possible. If up-time is critical, one should consider installing redundant in-cell sensors to provide an opportunity to remove one unit for repair or recalibration or replacement while the second unit covers on-going operations.

2. Designers should provide the means to remotely calibrate in-cell sensors from outside the cell. The techniques depend on the sensor and the application. Frequently, redundant sensors are used to measure a given parameter continuously, and portable sensors are used periodically to confirm the output accuracy of the fixed sensor. Fixed gage points or mechanical limits can be used to calibrate a position-measuring sensor. Other fiducial points can be used to calibrate different remote-environment sensors (e.g., electronic ice baths, remote load tests, fixtures, etc.)

3. If remote-environment sensors are unavoidable, then adjustment and calibration operations should be performed in-situ, wherever possible, using the remote-environment manipulator system. Performing these operations by contact means, in most cases, will require removal from the remote environment and decontamination of the sensor or mechanism or transfer to glovebox. 


\section{HUMAN-MACHINE INTERFACES}

\subsection{OPERATOR INTERFACE GUIDELINES}

Operator interface design must proceed systematically if it is to be effective. One approach is to follow three phases: (1) function analysis, (2) task analysis, and (3) design. In the first phase, the control requirements are identified and evaluated from an ergonomic perspective. This requires listing all functions that must be performed from the control room, organizing functions into related groups, and determining crew size and allocating functions to crewmembers. The outcome of this phase of the design is a function plan for the control room. The function plan identifies how many people will be needed to operate the system and what action each operator must take.

In the task analysis, the required tasks of operators must be listed, the relationships between tasks identified, and procedures for completing tasks must be developed. This requires listing the tasks and subtasks to be performed, structuring the tasks so that relationships are clearly identified, preparing a dynamic task analysis model, and evaluating options for completing tasks and alternative task procedures.

Identifying tasks proceeds alongside function identification and uses some of the same information. However, the task analysis should be more detailed. A task is a set of human actions requiring the achieving of a goal; in effect, the function list provides goals and the task analysis describes how users will complete them. Tasks include a stimulus, or cue, which starts the task, a set of task actions (perceptions, discriminations, decisions, control actions, or communications), and a stopping point that provides feedback of results. The outcome of this stage will be a list of tasks performed in the control room during a maintenance campaign. Structuring tasks means that they are organized in a meaningful fashion, most likely based on the order in which tasks are to be completed. The outcome of this stage will be a network chart showing how tasks will be carried out. Finally, the task analysis includes identification and evaluates options for completing tasks and alternative procedures. The outcome of this stage will be a set of recommendations for structuring maintenance campaigns to optimize the efficiency of the crew and equipment.

It is only after gathering function and task information that the design process may begin. The design begins with development of conceptual designs of control panels, workstations, and other aspects of human-machine interfaces. In this phase the functional organization developed in the first phase will be translated into recommendations for arranging physical components of the control room or control station. The outcome of this phase will be a set of conceptual design drawings describing workstation and control room or control station layout concepts.

Control panels are the building blocks of workstation design and include all displays and controls necessary for one operator to perform an activity for which he is responsible. The outcome of this part of the task will be conceptual designs for all of the control panels required by each crewmember.

Workstations include control panels and supporting equipment. Some crewmembers may require multiple panels (e.g., a control panel to turn on and initialize the equipment and a control panel to conduct manipulator operations); workstations will be designed to integrate or separate multiple control panels as necessary to optimize user efficiency. Workstations will also support the users by providing room for manuals, storage, etc., if necessary. The outcome of this part of the task will be conceptual design drawings for workstations, including recommendations for displays, controls, cabinets, and seating. 


\subsection{OPERATOR TRAINING GUIDELINES}

Development of training programs begins with identifying the functions to be performed by a system and the characteristics of the users of the system. This identification permits trainers to develop training approaches that match the needs of the mission and the capabilities of the users. Because CPU remote maintenance systems may operate in a variety of missions and with a variety of different types of users, training programs must, to a certain extent, be developed on an application-by-application basis. However, some principles for training may be developed from what is generally known about remote maintenance. These principles may assume a set of user characteristics based on the most likely set of candidate users. This permits behavioral objectives for a training program to be determined.

\subsubsection{User Characteristics}

The training needs analysis starts with identifying user characteristics, which concentrates on the knowledge, skills, and abilities that may be expected within the user population.

Ideally, users should be drawn from the population of operations workers within the deployment organization. Persons in this population will most likely have adequate skills for operating the systems, and the practice of using these workers avoids the higher labor costs associated with using engineering or management personnel. (Many of the skills required for remote operation may actually be comparatively rarer in the latter population).

The capabilities of users may be evaluated along two dimensions: cognitive abilities and psychomotor abilities. Table 2 lists psychomotor abilities and tentatively evaluates the importance of each successful completion of remote operator training and later operation of the system. Table 3 does the same for cognitive abilities.

From this tentative analysis, it appears that remote workers must be most skilled in the psychomotor areas of rate control and manual dexterity. Skills in control precision, multilimb coordination, arm-hand steadiness, reaction times, and response orientation will also be important. They must possess cognitive skills primarily in the areas of perceptual speed and spatial and mechanical ability. Reasoning ability, memory, and general clerical ability will also be important.

\subsubsection{System Needs}

System needs analysis involves an investigation of the organization within which workers function and the tasks which they must perform to develop task specifications which list the behaviors required of operators, the frequency of performance of each behavior, the importance of each behavior, and the difficulty of learning to perform the behavior successfully.

Because of the generic applicability of CPU remote maintenance systems to many specific applications, a complete and formal system needs analysis is not possible. Such an analysis requires reference to a specific application. However, examination of the function lists presented earlier permits a definition of some tasks that will be required in remote handling applications. The tasks are ones that may be applicable in either (1) a variety of applications or (2) clearly tasks that must be supported to meet the goals set for the system. Table 4 lists these tasks and makes a preliminary assessment of learning difficulty, given the user characteristics described above. It also lists the important psychomotor and cognitive abilities needed to carry out the task. 
Tables 2-4 points towards some training needs. First, it will be important to teach users to understand any computer menu structure that may be used so that they can quickly find any needed screens. Users must be able to identify which menu-based controls and displays that they need and quickly determine the menu navigation path that will take them to the appropriate screens. Training to use the menu system must concentrate on teaching the menu structure. This required having a good memory and retentive skills.

Second, being able to control the camera will be important for manipulation. This skill may require use of a menu to assign controls to one of a set of available cameras. This task will be affected by user training with the menu system. Once the proper camera control perform remote camera mapping is established, it will be necessary for operators to be able to quickly select which control they want to use (e.g., pan vs. zoom) and which way to activate the control to achieve the desired result. This involves, first, a good memory and then response orientation ability and armhand steadiness ability.

Training requirements for these tasks can be outlined, but final training requirements must be determined on an application-by-application basis.

Table 2. Psychomotor abilities and importance to remote operations.

\begin{tabular}{|c|c|c|c|}
\hline Psychomotor Area & Description & Importance & Example \\
\hline Control precision & $\begin{array}{l}\text { Ability to make accurate } \\
\text { control inputs using large } \\
\text { muscle groups }\end{array}$ & Moderate & $\begin{array}{l}\text { Menu item selection using } \\
\text { touch screen or mouse }\end{array}$ \\
\hline Multilimb coordination & $\begin{array}{l}\text { Ability to use sets of limbs to } \\
\text { make inputs }\end{array}$ & Moderate & $\begin{array}{l}\text { Simultaneously position and } \\
\text { operate a remote tool }\end{array}$ \\
\hline Rate control & $\begin{array}{l}\text { Ability to control the speed } \\
\text { and direction of travel of a } \\
\text { moving object }\end{array}$ & High & Remote driving \\
\hline Arm-hand steadiness & $\begin{array}{l}\text { Ability to position arms and } \\
\text { hands precisely without large } \\
\text { force required }\end{array}$ & Moderate & $\begin{array}{l}\text { Menu item selection using } \\
\text { touch screen or mouse }\end{array}$ \\
\hline Finger dexterity & $\begin{array}{l}\text { Ability to make precise, } \\
\text { skilled movements of the } \\
\text { fingers }\end{array}$ & Low & Typing \\
\hline Manual dexterity & $\begin{array}{l}\text { Ability to make accurate arm- } \\
\text { hand movements quickly } \\
\text { while moving relatively large } \\
\text { loads }\end{array}$ & High & Remote manipulation \\
\hline Reaction time & $\begin{array}{l}\text { Ability to respond rapidly to } \\
\text { stimuli }\end{array}$ & Moderate & Responding to alarms \\
\hline Response orientation & $\begin{array}{l}\text { Ability to rapidly select the } \\
\text { appropriate control from a } \\
\text { set, and make the appropriate } \\
\text { input using that control }\end{array}$ & Moderate & $\begin{array}{l}\text { Camera control; choosing } \\
\text { the correct zoom, focus, or } \\
\text { iris control }\end{array}$ \\
\hline Speed of arm movement & $\begin{array}{l}\text { Ability to make rapid arm } \\
\text { movements without any } \\
\text { accuracy requirement }\end{array}$ & Very low & None \\
\hline
\end{tabular}


Table 3. Cognitive abilities and their respective importance for RoboCon (from [6]).

\begin{tabular}{|c|c|c|c|}
\hline Cognitive Area & Description & Importance & Example \\
\hline General mental ability & $\begin{array}{l}\text { Ability to understand verbal } \\
\text { and numerical concepts, } \\
\text { underlying principles, and to } \\
\text { reason and solve problems } \\
\text { using abstract patterns or } \\
\text { symbols }\end{array}$ & Low & None \\
\hline Verbal ability & $\begin{array}{l}\text { Ability to comprehend and } \\
\text { use language }\end{array}$ & Low & Mission planning \\
\hline Quantitative ability & $\begin{array}{l}\text { Ability to comprehend and } \\
\text { use mathematics }\end{array}$ & Low & Mission scheduling \\
\hline Reasoning ability & $\begin{array}{l}\text { Ability to think logically and } \\
\text { clearly }\end{array}$ & Moderate & $\begin{array}{l}\text { Understanding relationships } \\
\text { among remote elements; } \\
\text { system diagnosis }\end{array}$ \\
\hline Perceptual speed & $\begin{array}{l}\text { Ability to perceive detail } \\
\text { quickly and accurately }\end{array}$ & High & Remote viewing \\
\hline Memory & $\begin{array}{l}\text { Ability to learn, recall, and } \\
\text { reproduce information }\end{array}$ & Moderate & Menu navigation \\
\hline $\begin{array}{l}\text { Spatial and Mechanical } \\
\text { ability }\end{array}$ & \begin{tabular}{lrr}
\multicolumn{3}{l}{ Ability to understand spatial } \\
relationships and & to \\
understand and & apply \\
manipulations & of & those \\
relationships & &
\end{tabular} & High & Remote manipulation \\
\hline General clerical ability & $\begin{array}{l}\text { Ability to quickly and } \\
\text { accurately perform clerical } \\
\text { tasks }\end{array}$ & Moderate & Recording important events \\
\hline
\end{tabular}

Table 4. Partial task list with skill requirements.

\begin{tabular}{|c|c|c|c|l|}
\hline Task & Frequency & Importance & Learning Difficulty & \multicolumn{1}{|c|}{ Abilities } \\
\hline Graphic menu operations & Moderate & High & Low & $\begin{array}{l}\text { Memory; arm-hand } \\
\text { steadiness }\end{array}$ \\
\hline Viewing system control & High & High & Moderate & $\begin{array}{l}\text { Memory; arm-hand } \\
\text { steadiness; response } \\
\text { orientation }\end{array}$ \\
\hline Remote manipulation & High & High & High & $\begin{array}{l}\text { Perceptual speed; } \\
\text { spatial/mechanical } \\
\text { ability; rate control; } \\
\text { arm-hand steadiness; } \\
\text { multilimb } \\
\text { coordination }\end{array}$ \\
\hline Tool operation & Moderate & High & Low & $\begin{array}{l}\text { Perceptual speed; } \\
\text { spatial/mechanical } \\
\text { ability; arm-hand } \\
\text { steadiness; multilimb } \\
\text { coordination }\end{array}$ \\
\hline
\end{tabular}




\subsubsection{Training Techniques}

Many methods or techniques for training are available; examples include lectures, audiovisual instruction (video or audio tapes, slides, etc.), self-instruction (programmed instruction or computerassisted instruction), case study, simulation, and modeling. For CPU remote maintenance systems, as for any other human-machine system, the challenge is selecting the appropriate mix of techniques to best fit the training requirements of the system and the characteristics of potential users.

Simulation of real operations for training should be considered to include performance of real tasks using mock-ups. This sort of exercise provides the most nearly accurate modeling of realworld tasks and should result in the highest transfer of training, providing that the task mock-ups are accurate.

Both computer aided intelligence (CAI) and simulation are capable of meeting the psychomotor and cognitive abilities needs of remote maintenance system users and, with thoughtful development, can be tailored to meet the capabilities of any pool of potential users. Other techniques may be useful as supplements. For example, lectures and group discussions of training exercises could be used to highlight key features of the interface and introduce trainees to the goals and requirements of the training. However, the fundamental training techniques should be computer-assisted instruction and simulation in order to provide the best transfer of performance from training to actual operations.

\subsubsection{An Instructional Program Outline}

To this point, we have identified the key training needs and a preferred user population and have selected instructional techniques. The next stage of training program development is to create a training sequence, including a list of training exercises to be completed, the behavioral objectives for each task, the training technique to be used, and the specific training needs to be addressed by each exercise.

Table 5 outlines an instructional program for CPU remote maintenance system users. It is based on the instructional techniques described previously and on the concept of part-task training, which is an assumed idea that complex skills may be learned by attaining proficiency on sub-tasks comprising the complex skill before the trainee attempts to complete the whole task. This approach divides the learning into reasonable units, or chunks, which may be easily mastered. Early tasks in the training sequence concentrate on the trainee's attaining proficiency with a component; as trainees proceed through the sequence the sub-tasks are gradually assembled into a full-blown system operation. This is clear from the "Needs addressed" column of Table 5, which shows greater numbers of the training needs addressed by each succeeding exercise. Each exercise builds on the preceding one until the trainee attains complete mastery of the system.

The instructional sequence, as outlined in Table 5, paints the training program with broad strokes. Each stage in the sequence may require multiple repetitions of the exercise listed to attain proficiency, and full coverage of system features may require that each exercise in the table be, in fact, a set of exercises. Full details of a training program are beyond the scope of this document. 
Table 5. Instructional sequence.

\begin{tabular}{|c|c|c|c|}
\hline Exercise & Objectives & Technique & Needs Addressed \\
\hline $\begin{array}{l}\text { Remote maintenance } \\
\text { briefing }\end{array}$ & $\begin{array}{l}\text { 1.Trainees will become } \\
\text { familiar with controls and } \\
\text { displays. } \\
\text { 2. Trainees will be prepared for } \\
\text { operation in later exercises. }\end{array}$ & $\begin{array}{l}\text { Lecture, } \\
\text { audiovisual, or } \\
\text { CAI }\end{array}$ & Response orientation \\
\hline $\begin{array}{l}\text { Menu structure } \\
\text { introduction (if necessary) }\end{array}$ & $\begin{array}{l}\text { Trainees will become } \\
\text { familiar with the arrangement } \\
\text { of menu screens }\end{array}$ & CAI & Memory; response orientation \\
\hline $\begin{array}{l}\text { Menu operation (if } \\
\text { necessary) }\end{array}$ & $\begin{array}{l}\text { Trainees will learn to } \\
\text { navigate through the menu } \\
\text { structure to find screens } \\
\text { needed at various mission } \\
\text { phases }\end{array}$ & CAI or simulation & $\begin{array}{l}\text { Memory; response orientation; } \\
\text { arm-hand steadiness; control } \\
\text { precision }\end{array}$ \\
\hline Camera control & $\begin{array}{l}\text { Trainees will learn to use } \\
\text { video cameras to inspect a } \\
\text { remote environment }\end{array}$ & $\begin{array}{l}\text { Mock-ups or } \\
\text { simulation }\end{array}$ & $\begin{array}{l}\text { Memory; response orientation; } \\
\text { perceptual speed; arm-hand } \\
\text { steadiness; control precision }\end{array}$ \\
\hline Remote operations & $\begin{array}{l}\text { Trainees will become } \\
\text { proficient at operating remote } \\
\text { systems in the context of } \\
\text { small-scale tasks }\end{array}$ & $\begin{array}{l}\text { Mock-ups or } \\
\text { simulation }\end{array}$ & $\begin{array}{l}\text { Rate control; arm-hand } \\
\text { steadiness; manual dexterity; } \\
\text { response orientation; } \\
\text { perceptual speed; } \\
\text { spatial/mechanical }\end{array}$ \\
\hline Mission completion & $\begin{array}{l}\text { Trainees will demonstrate } \\
\text { ability to complete a typical } \\
\text { mission }\end{array}$ & $\begin{array}{l}\text { Mock-ups or } \\
\text { simulation }\end{array}$ & All \\
\hline
\end{tabular}




\section{STRUCTURAL AND MATERIALS DESIGN GUIDELINES}

The choice of materials for the design of equipment or systems that are to be maintained remotely is critical. As with any conventional mechanical design, strength and wear properties are important to ensure long operating life and to increase the mean time between failures; however, these are not the only issues, nor are they necessarily the issues that govern the design of a particular component.

Density of the material is important because the remote handling system must be capable of manipulating and lifting the components and subassemblies. Typical mechanical master/slave systems can handle payloads on the order of $50 \mathrm{~kg}$. and hydraulic manipulator systems are capable of handling $100 \mathrm{~kg}$. Low-density, high-strength materials (i.e., titanium) reduce weight without sacrificing strength.

Material surface properties such as hardness are also important. Soft materials are susceptible to galling and subsequent jamming when they are connected to other materials. Consequently, material hardness is critical in the design of pins, guides, sliding components and especially threaded members.

Corrosion resistance is certainly important for parts that are placed in highly corrosive environments. The environment in and around the CPU is not highly corrosive, but because of the use of water in the processing of the waste and potential for the waste itself to cause corrosion, attention should still be given to corrosion resistance. Equipment designed for use in corrosive hot cells is generally made from stainless steel. Types 304L and 347 stainless steel in the as-welded condition and types 316 and 316L stainless steel in the annealed condition has good resistance to corrosion and is a good choice for critical components. For highly corrosive environments, the use of 400-series steels or cast chromium steels is not recommended (ref. 1). Aluminum alloys are good for corrosion resistance as well as are glass, polyethylene, and polyvinyl chloride.

Corrosion resistance is certainly important for parts that are placed in highly corrosive environments, but it is also important for items that slide or are threaded. Corroded bolts and nuts are very difficult to remove and could seriously affect maintenance time for a remotely maintained system. As previously mentioned, stainless steel is often selected as a corrosion-resistive material. Although good for resistance to corrosion, stainless steel is susceptible to galling. Galling (also called scuffing, scoring, and seizing) is a type of wear that occurs due to adhesion between two contacting surfaces exhibiting asperity that are welded and then sheared by the relative motion between closely mated sliding parts (ref. 2). Strong adhesion will transfer material from one part to the other and weak adhesion will create loose particles. Severe galling will cause surface failure of the parts and the moving parts may seize. Designers of remotely maintained systems must give special attention to galling. The onset of galling is not easily detected using remote manipulators and is almost undetectable when using remotely operated power tools such as remotely driven impact wrenches. Careful selection of materials having different hardnesses and careful use of proper lubrication will help to prevent galling. For the CPU, the following guidelines should be followed for closely mating parts such as guide pins and threaded members. 
1. Deburr and clean all threads.

2. Lubricate parts whenever possible. Reference 1 provides a good list of radiation-resistant lubricants. Typical lubricant dose limits range in the $10^{8}$ to $10^{9}$ rads.

3. Properly select materials for mating parts. Nitronic $60^{\mathrm{TM}}$ is a trade name for a material that exhibits antigalling properties. Tests have shown that a precipitation-hardened (17-4 PH) bolt with a Nitronic nut is better at resisting galling than a Nitronic bolt with a hardened nut. ${ }^{1}$ Typical galling pressures for steel on steel are 2000 psi, and for Nitronic 60 combinations, it is 50,000 psi. Wear factors (the amount of material removed in milligrams after 1,000 cycles on a Taber metal abrader machine) range from 10 to 2 , respectively.

4. Provide a pilot lead to start bolts to avoid cross threading. Blunting the starter threads is also useful.

5. Design mating parts and assemblies for easy alignment. Misalign threads have increased susceptibility to galling. Use alignment pins, guides, and supports to improve initial mating and to ensure positive alignment. Try to load screw fasteners in tension only, avoiding shear. Considering galling, using a screw fastener to pull mating parts together is bad design practice.

Radiation resistance is important for equipment designed for remote maintenance. Many materials degrade significantly in a high radiation environment. Radiation produces microscopic changes in the composition and structure of materials. These minute changes create no initial observable effects on the physical, chemical, or biological properties of the material. However, given a sufficient number of these changes over time, the properties of the material are affected. The nature and extent of the changes brought about by exposure to radiation depends upon the type of material being exposed, the amount of radiation absorbed, the other environmental conditions, and the application of the material. The performance of a component in a radiation environment is affected through the degradation of its particular parts. Metals and ceramics tend to deteriorate much slower than do organic materials, plastics, elastomers, lubricants, seals, hoses, hydraulic fluids, and viewing windows. Typical materials show moderate degradation at gamma radiation does of $10^{7}$ to $10^{8} \mathrm{rad}$ and severe failure at $10^{9} \mathrm{rad}$ or greater. Appendix B of ref. 1 has detailed information on the radiation resistance of various materials as well as does ref. 5. In addition, detailed information of the effects of radiation on components is provided in refs. 6-10. If an acceptable compromise cannot be reached with the selection of material, radiation life, and location inside the radiation environment, then shielding must be used. This shielding, however, is likely to complicate remote maintenance.

Material properties such as resistance to wear, resistance to radiation damage, galling resistance, strength, resistance to corrosion, etc. are important. As the mean time between failures from wear and environmental conditions increases then maintenance requirements decrease. The reduction in maintenance requirements is essential for remotely maintainable systems and equipment. 


\section{MECHANICAL DESIGN CONSIDERATIONS}

Proper mechanical design has a significant impact on the maintenance requirements and on the time needed to perform maintenance for any system and especially for systems designed for remote maintenance. Obvious mechanical design approaches for remotely maintained equipment is to (1) use simple parts, (2) design manageable modules, and (3) include mechanical aids for manipulation (these approaches are discussed in Sect. 3.5). Other considerations are discussed in the following.

Avoid the design of parts, components, and assemblies with difficult alignments (e.g., shafts, holes, tabs, etc.). Assembly with these types of alignments should be done outside of the remotehandling environment, and the resulting completed assembly should be treated as a module. Mating

parts with high tolerances should be avoided. Obviously, loose connections are easier to accomplish with remote manipulators. Any time that assembly is required in the remote environment, guides, pins, and supports should be used. The "self assembly" concept should apply only where components and modules rest upon supports and/or follow guides and can essentially "fall" into place. Simple latches can then be used to hold them in place.

Multiple connecting parts at a single point of assembly should be avoided. At most, one component or module should be moved into place at any one time. Assembling three or more components usually requires too much dexterity or too many manipulators in the same working space. Inability to view properly is also a problem when too many objects and manipulators are in the same working volume.

Welding and cutting are very difficult to accomplish remotely. Only very structured welds and cutting assemblies are amenable to robotic and telerobotic operation. Otherwise, these should be avoided.

Fastener concepts (such as those discussed in Sect. 3.5) should be employed. Bolts with tapers, pilot leads, starter threads blunted, and captured bolts (see Fig. 12) and nuts are all good design practice for systems and equipment that are to be maintained remotely. 


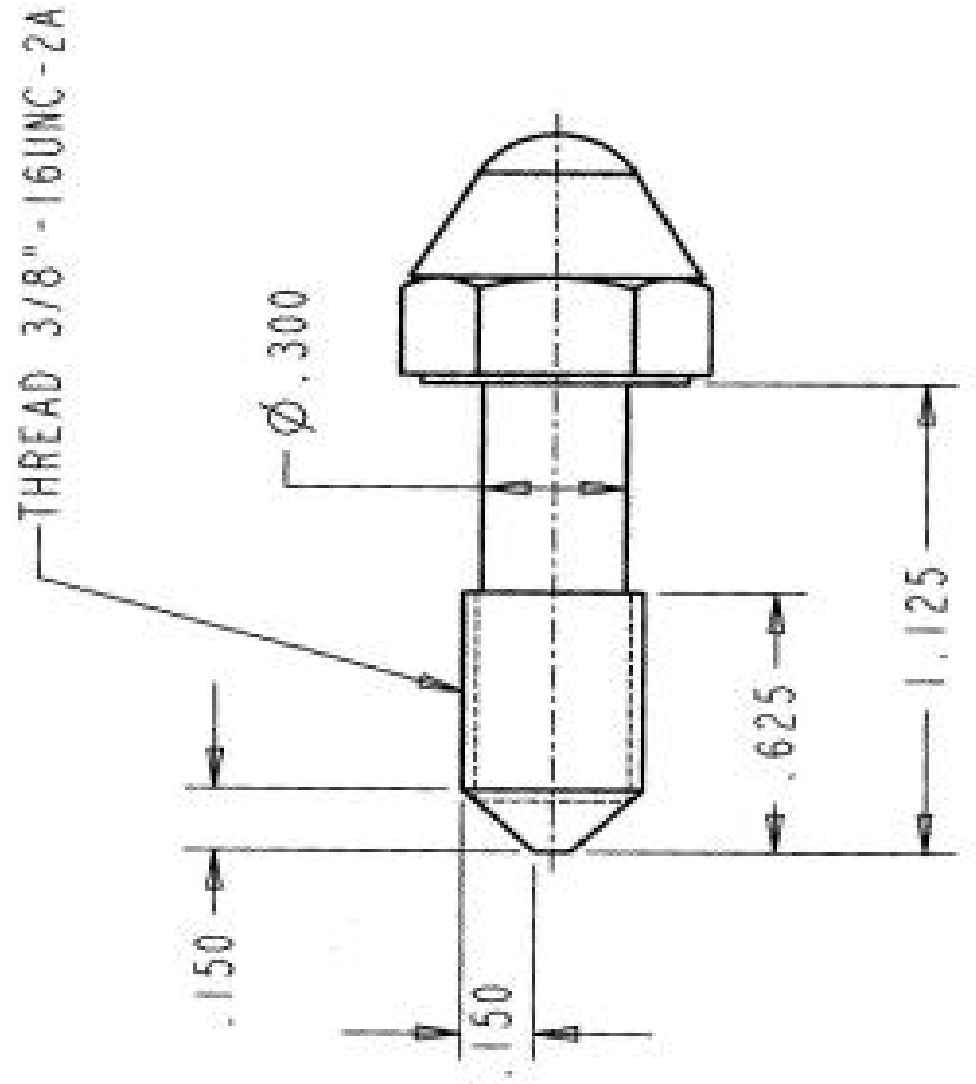

Fig. 12. Captured bolt design. 




\begin{tabular}{|c|c|c|c|c|}
\hline BOLT SIZE (A") & "B* & "C" & $\mathrm{B}^{*}$ & $\mathrm{C}^{*}$ \\
\hline 3/8 UNC 16-2A & 0.38 & 0.30 & 0.28 & 0.06 \\
\hline $1 / 2$ UNC 13-2A* & 0.50 & 0.40 & 0.38 & 0.06 \\
\hline $3 / 4$ UNC 10-2A & 0.70 & 0.63 & 0.50 & 0.06 \\
\hline 1 UNC 8-2A & 0.90 & 0.85 & 0.50 & 0.12 \\
\hline $11 / 4$ UNC 7-2A & 1.10 & 1.07 & 0.63 & 0.12 \\
\hline
\end{tabular}

*a minimum of class za threads are required with 3A OPTIONAL.

Fig. 13. 


\section{ELECTRONICS: CABLES, AND ELECTRICAL CONNECTORS}

\subsection{CABLES}

For discussion in the context of remote maintenance systems, electrical cables are divided into two categories: electrical device cables and connecting cables. Electrical device cables carry power or information signals from an electrical device (e.g., a motor, a sensor, a camera, etc.) to a junction box. Connecting cables connect junction boxes to other junction boxes or to exit ports from the remote cell. Electrical device cables should be connected on the device end (i.e., on the motor, sensor, camera, etc.) in a conventional manner, that is, with soldered screw terminals and strain relief or bushings that structurally secure the cables. The junction box end of an electrical device cable should have a connector designed for remote maintenance. With this design, the electrical device can be removed with its associated cable while reducing the likelihood of cable failures occurring between the cable and the device. If cost is a significant issue, connecting cables should have conventional connectors at both ends, since they are not high maintenance items. If cost is less of a consideration, then one can use a remotely maintainable connector on both ends of the connecting cables.

Cable carriers need to be designed for all cables in a remote environment but especially for cables that are designed to accommodate relative motion between devices and connections. Flexing should be provided according to national code guidelines for the diameter of the cable being bent. Spring supports, festoons, and flexible cable ways are all acceptable means of support if normal remote maintenance guidelines are followed (e.g., select the proper material, avoid obstruction of nearby equipment, design for remote maintenance).

\subsection{CONNECTORS}

Electrical connectors are used to transfer power and to transmit signals and data. In usual practice, power and signal lines are not mixed together so as to avoid noise and electrical interference. However, they are often placed in a single tether for remotely operated vehicles. Electrical connector selection for systems targeted for remote maintenance is highly dependent upon the respective remote maintenance system and its capabilities. As mentioned previously, most remote maintenance systems include manipulators having parallel-jaw-type grippers. Tests at ORNL have shown that dexterous, force-reflecting manipulators fitted with parallel-jaw grippers can service some commercially available connectors. However, electrical connectors should have several desirable characteristics for remote maintainability. These are summarized in the following paragraphs.

Two general types of electrical connectors are used in hot cells: those that transmit electrical power and those that transmit data. Dual function connectors are rare because of the noise and interference. As was noted for fluid connectors, the choice of an electrical connector depends on the capabilities of the remote maintenance system available to handle the connector. For the maintenance systems installed in many of the older process cells, rugged, bulky, especially designed connectors with precision mating features must be used to prevent damage to the connector bodies and pins. For servo- or mechanical manipulators, more conventional electrical connectors can be used. Tests at ORNL, using dexterous, force-reflecting servomanipulators demonstrated that several commercially available connectors could endure repeated handling without damage to the connector pins or bodies. These tests also identified several desirable features for electrical 
connectors that are applicable to both special and commercially available units. These are listed below.

1. Connectors that require a push-pull type motion for operation are preferred over those requiring rotary motions for mating. If rotary motion is necessary, then the number of revolutions should be minimized. Tests need to be done to determine if combined rotary push-pull connectors (e.g., BNC-like) are acceptable.

2. Angled connectors $\left(90^{\circ}\right)$ of the push-pull design promote ease of handling compared to inline straight connectors. The electrical lines on an angled connector do not interfere with the manipulator grip, and remote viewing of the handling operation is improved. Rotary locking type connectors are not well suited to angle models. A connection to the underside of a horizontal face should be avoided but, if necessary, favors an in-line connector.

3. Connector bodies with flat, parallel surfaces are easier to grip with manipulator tongs than are cylindrical bodies. Knurling on the gripping surfaces aids remote operability, especially for rotary motion connectors. A connector with a lanyard design for unplugging provides an alternative way to disconnect, but it introduces a potential tangling hazard, and a gripping surface is still required for rejoining.

4. Connectors with stepped inserts containing both pins and sockets in each mating half are preferred over pins only in one-half and all sockets in the other. The stepped feature provides an alignment feature that can be "felt" by a force-reflecting servomanipulator and that can effectively minimize pin damage.

5. Any alignment guides or orientation guides (e.g., flattened sides, guide pins, and alignment grooves) must be visible even after the connection is made. Many commercially available connectors have guide services, however, these are often obscured once the connections are made. These connectors are extremely difficult to connect remotely.

6. Servomotor connections having both power and signal lines terminating in a single connector are helpful for remote maintenance. The ORNL-designed Advanced Servomanipulator had this feature (ref. 11).

Several design guidelines apply to electrical connectors and jumpers, which are listed below.

1. Provide sufficient length for strain relief such as to minimize cable damage however, not so much as to encounter a tangling hazard during operation or replacement.

2. Position the mounting of the electrical connectors for ease of viewing by the remote operator.

3. Avoid the use of set screws.

4. Use visible and permanent alignment marks to promote engagement of mating pieces.

5. Select materials compatible with the remote cell environment (i.e., austenitic stainless steels for connector bodies, ceramic inserts, noble metal plating on pins and sockets, hermetically sealed units, etc.) 


\section{REMOTE MAINTENANCE AND SUPPORT EQUIPMENT}

Different remote maintenance "systems" are available. An unprotected, skilled, human technician is the first alternative, but a person is not usually selected as an alternative for highly contaminated systems. A suited technician can be used. If the system is portable, small, or can be disassembled into appropriately sized subsystems and components, then it can be maintained in a glovebox environment. Master/slave manipulator systems can be used and both force-reflecting and non-force-reflecting versions are applicable. Autonomous robots can also be used; however, their applicability is limited to tasks that can be well defined. Many researchers have attempted to determine the difference in time required maintaining a system by hand versus by suited personnel using manipulators, etc. Conventional rhetoric states that manipulators are usually an order of magnitude slower than are humans. We feel that this is completely erroneous. In reality, there is not one general fixed ratio between time to complete a task using manipulators versus completing the task by hand. This ratio is task dependent. This is not difficult to understand when it is pointed out that the ratio might well be one to infinity if a task is so hazardous that it cannot be done by hand at all. One should simply claim that, in general, completing a task with a manipulator takes longer than doing the same task by hand, provided that task can be done by hand.

\subsection{MANIPULATORS}

Often, manipulators serve as the maintenance interface for a remotely maintained system. If it is determined that a manipulator system is required to maintain a system, then many issues relevant to the manipulator system must be considered.

What are the manipulator system's limitations? Can it reach all areas of the device or system that is to be maintained? If it reaches all regions, can it then manipulate (i.e., position and orient) objects appropriately? What is the lift capacity of the manipulator system? Can it handle most of the maintenance modules without additional systems?

\subsection{VIEWING SYSTEMS}

Television and direct viewing systems are the operator's primary access to the remote system. Multiple camera views are required to adequately complete most remote maintenance tasks. Pan and tilt units on some of the remote cameras are often necessary to provide views of all or most areas and to aid in smooth maintenance. Stereo vision is usually not necessary. Camera systems designed to track the end point of the manipulator have not been proven to improve overall efficiency or to reduce operator fatigue.

\subsection{LIGHTING}

Lighting is critical for remote operations. Task illumination decreases task completion time and decreases operator fatigue. Sufficient lights should be placed from several different angles so to adequately illuminate the task components. 


\subsection{HOISTS}

Remotely operable hoists are a necessary addition to most remote handling systems because the weight of some of the components that must be manipulated in the remote environment frequently exceeds the capacity of the manipulator system(s) selected for the maintenance task. These should be capable of easy operation by either the primary operator or a secondary assistant.

\subsection{TOOLS}

Many examples of remote environment tools currently exist (e.g., impact wrenches, nutrunners, hydraulic cutters, saws, drills, remote characterization instruments, grinders, and pipe cutters). Items to consider when specifying a tool for a use in a remote environment include the following.

1. What are the size and weight of the tool and the loads associated with its power and control connections?

2. Can the tool be operated with the manipulator's gripper system, especially if the gripper is a parallel-jaw type gripper?

3. What level of dexterity is required to operate the tool effectively?

4. Can the tool be decontaminated for use in other remote environments or for repair?

5. How reliable is the tool?

6. What are the primary failure mechanisms of the tool, and will it fail safely?

7. What is the overall cost of the tool? 


\section{REMOTELY MAINTAINABLE FLUID CONNECTORS}

Remote operations on pipe connections are extremely common in process cells and will be very common in CPUs. This section shows some of the commonly used remote-environment piping connectors. TRU connectors can be used for straight-through connections, whereas, the Hanford-Purex connectors must have a right angle connection. Leak rates for the Hanford-Purex connectors range from $\mathrm{O}\left(10^{-9} \mathrm{~L} / \mathrm{s}\right)$ to $\mathrm{O}\left(10^{-7} \mathrm{~L} / \mathrm{s}\right)$, depending upon seal type and connector load (ref. 1). Figures 13-20 show several fluid connectors.

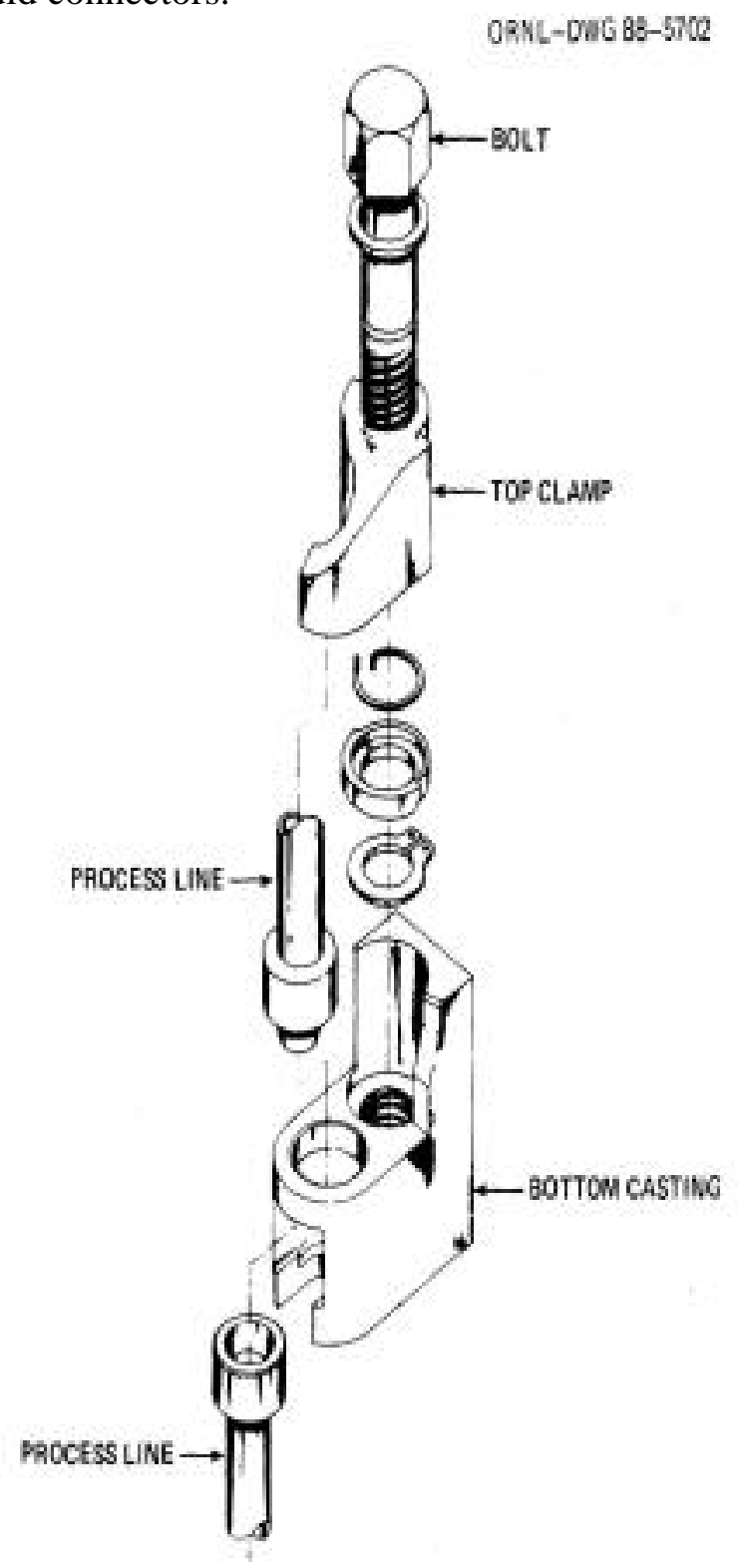

Fig. 13. The TRU connector. 


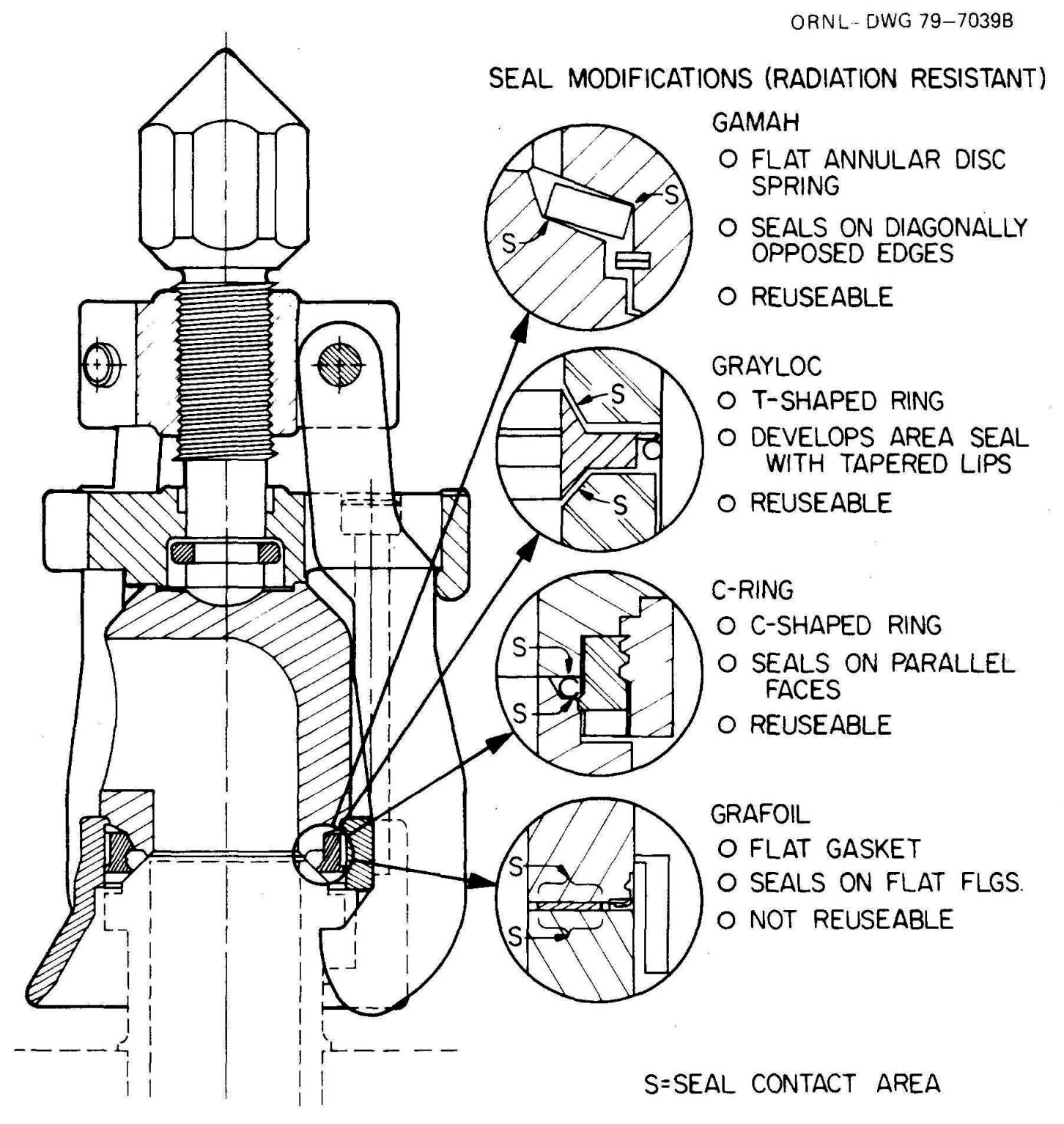

Fig. 14. The Hanford-Purex 3-jaw connector. 


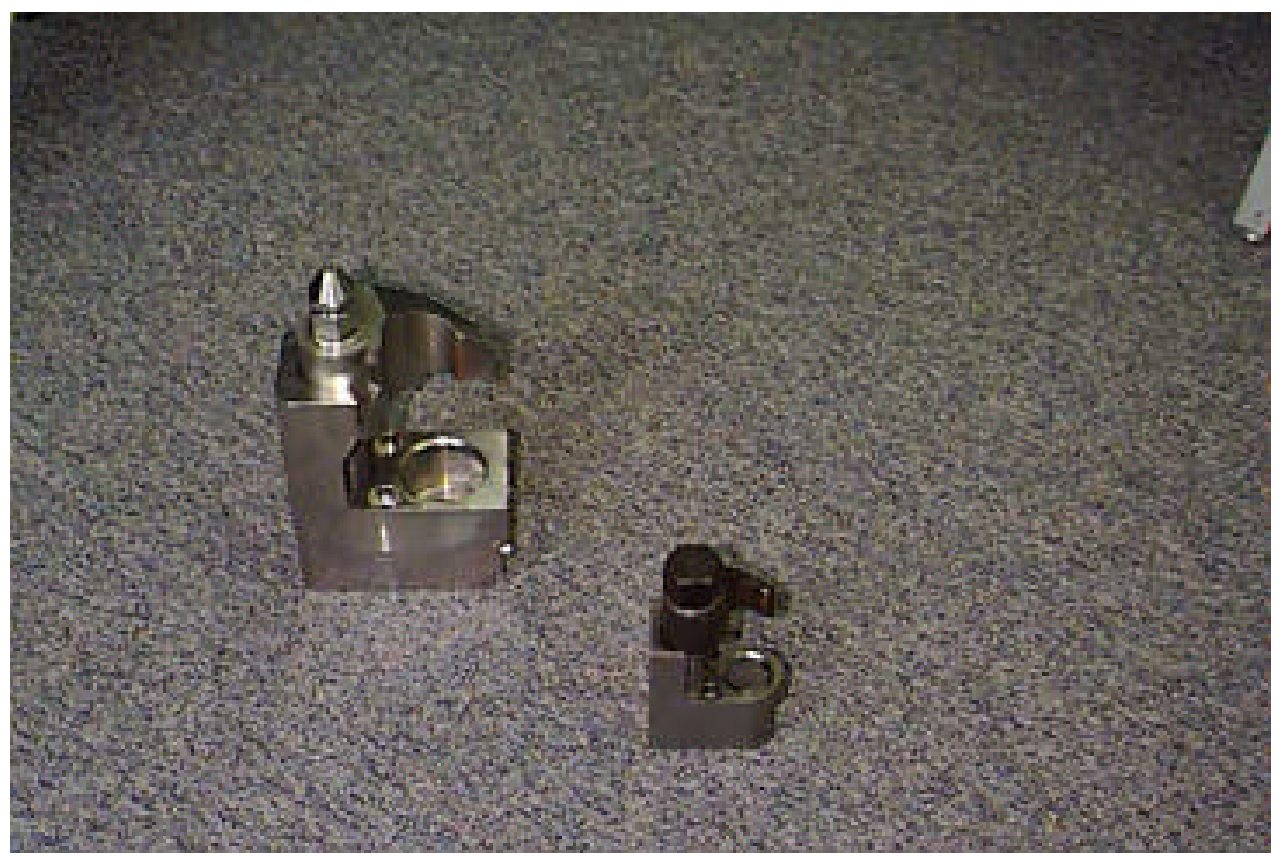

Fig. 15. Two examples of TRU connectors for straight through pipe connections. Note the conical head on the one in the background.

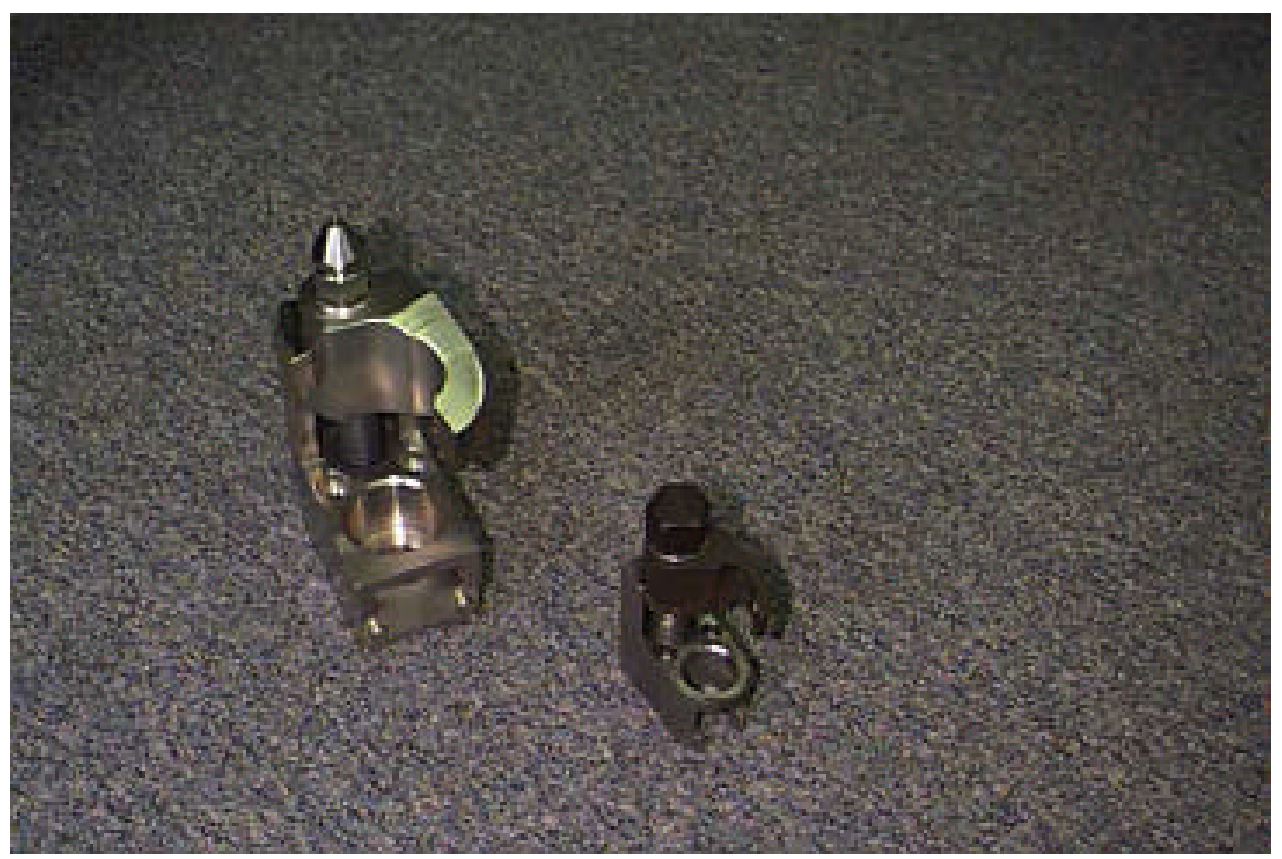

Fig. 16. Another view of the TRU connectors. The one on the left is the double-cam type and the one on the right is the spring-actuated type. 


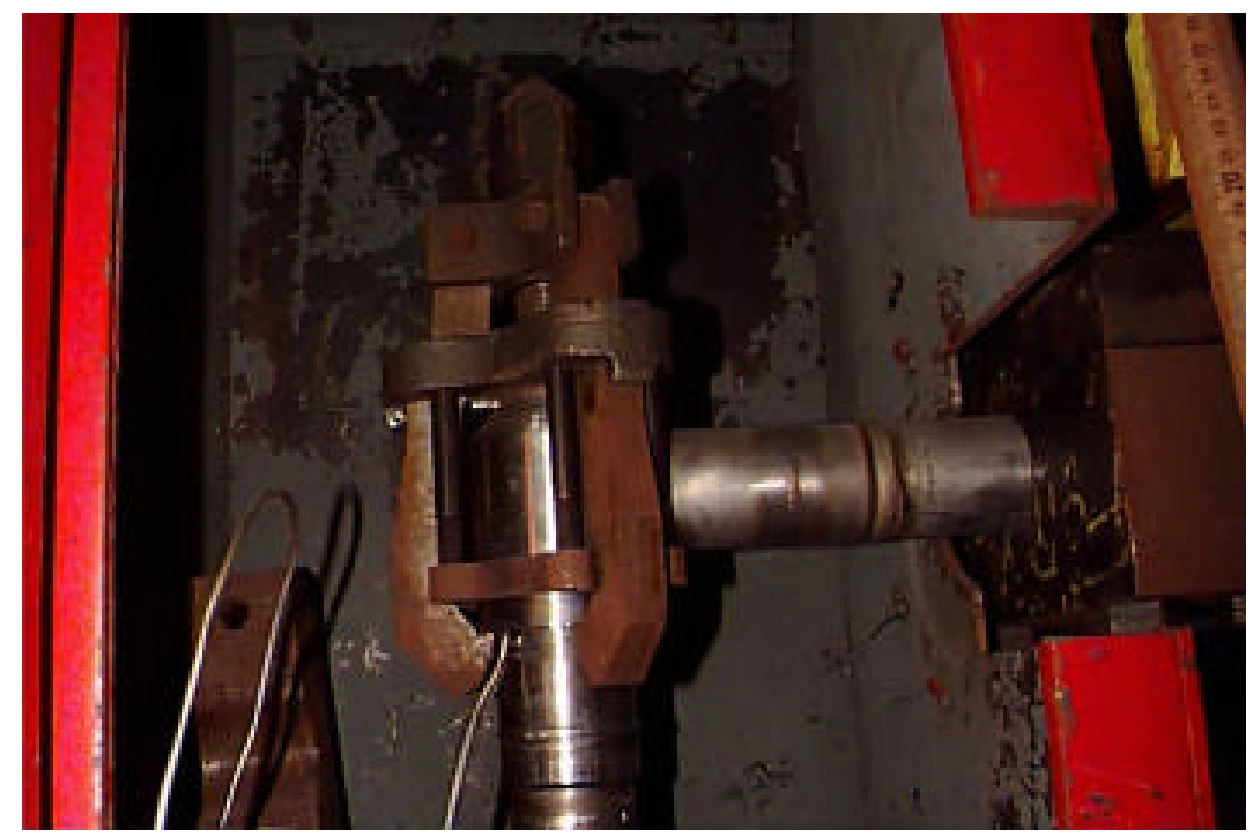

Fig. 17. Hanford-Purex connector for right-angle pipe connections.

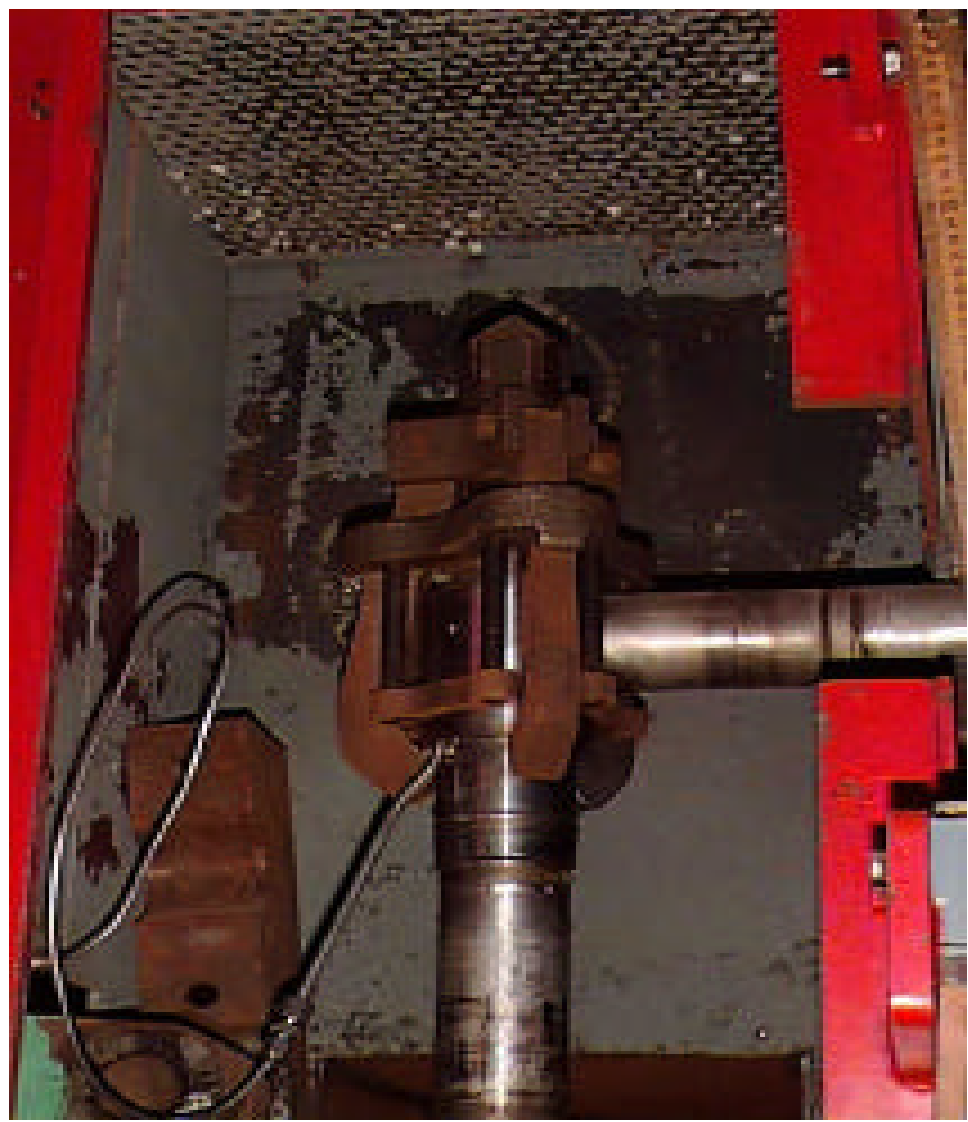

Fig. 18. Another view of the Hanford-Purex connector. 


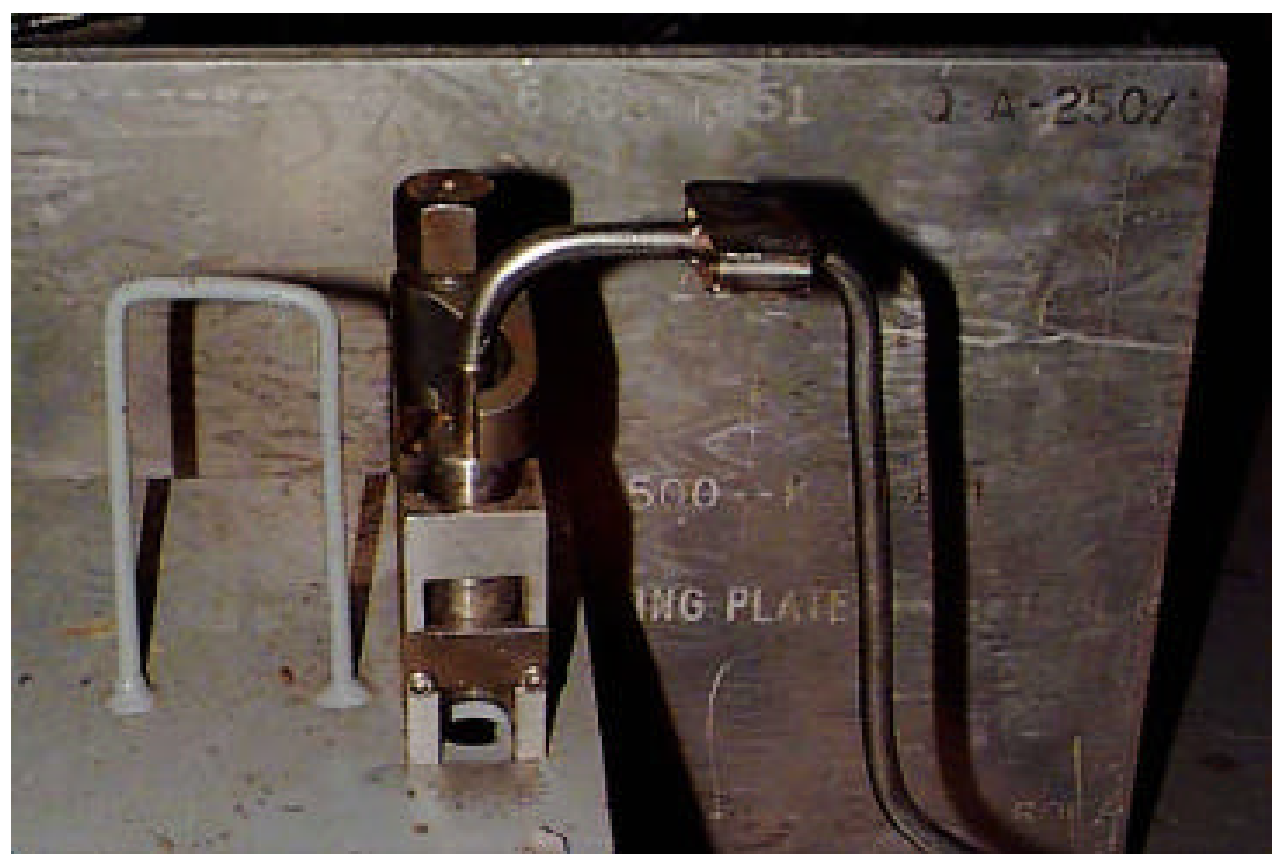

Fig. 19. A TRU connector with a pipe. Note the flat grip handle on the pipe for easier removal with a parallel-jaw type gripper. Also note the lifting bale on the connector base plate.

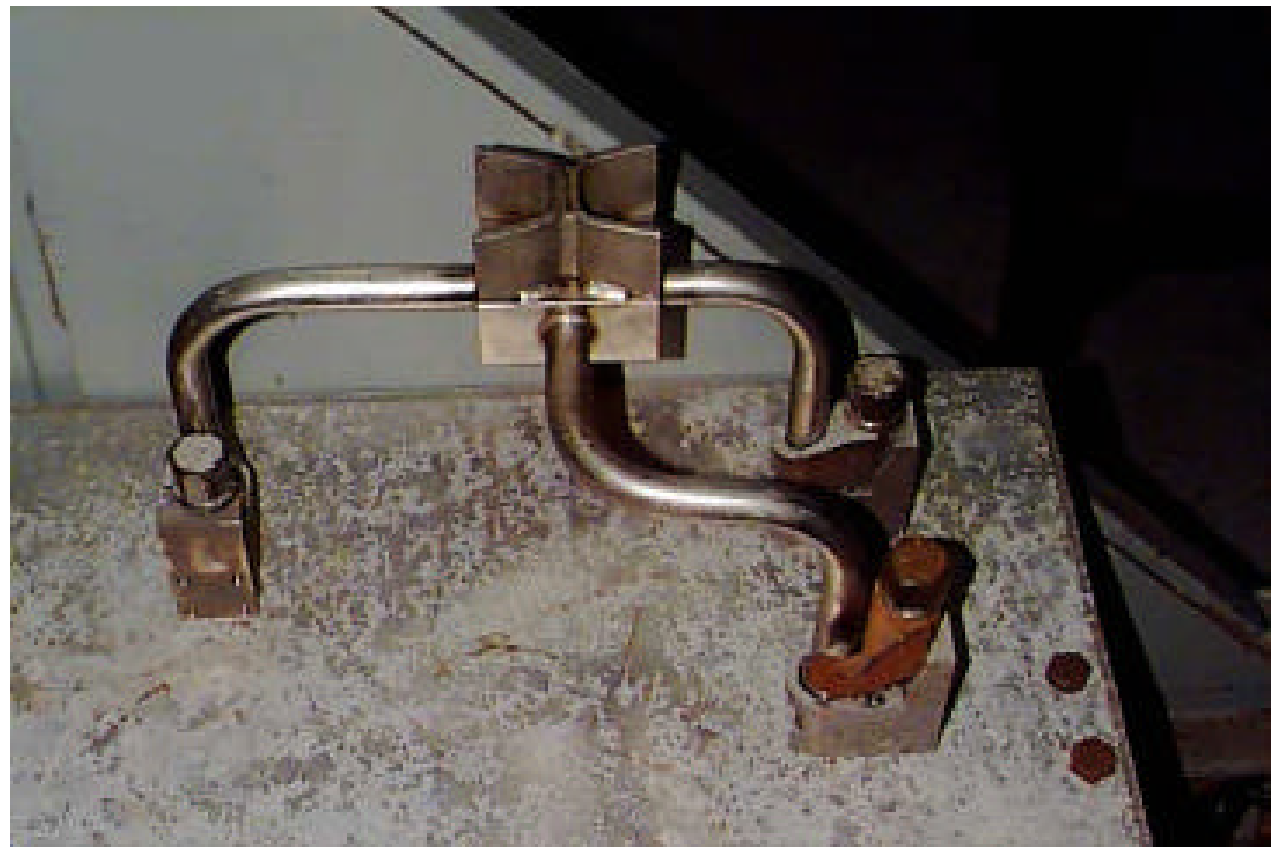

Fig. 20. Several TRU connectors with a mixing/splitting line. Note the grip handle on the pipe.

TRU connectors are just one of several choices. However, they are limited in size. Swedgloc and Hiltop are good alternatives and better choices if dexterous main (sp???) are provided. Hanford Purex connecttors are for larger pipes. Again, there are many choices here depending on remote handling capabilities. 


\section{GLOSSARY AND ACRONYM LIST}

Asperity (asperities): Roughness of surface, unevenness.

Galling (also called scuffing, scoring, and seizing): A type of wear that occurs due to adhesion.

Radiation Absorbed Does (rad): The dose from any radiation measured by the energy absorbed by a given mass of material. One rad is equal to $100 \mathrm{erg} / \mathrm{g}$ absorbed by a given material. When using rads, the material must be specified [e.g., rad (tissue), rad (carbon), etc.].

Compact Processing Unit: A minimally sized operating assemblage of processing equipment that performs a specified function.

Mechanical Master-Slave Manipulator: Remote handling tool featuring a mechanical arm in the remote area and an identical controller arm in the local area, connected by mechanical linkages, as opposed to electrical or electronic ones.

\section{ACRONYM LIST}

$\begin{array}{ll}\text { CAI } & \text { Computer Aided Intelligence } \\ \text { CPU } & \text { Compact Processing Unit } \\ \text { DOE } & \text { Department of Energy } \\ \text { DWPF } & \text { Defense Waste Processing Facility } \\ \text { MSM } & \text { Master-Slave Manipulator } \\ \text { ORNL } & \text { Oak Ridge National Laboratory } \\ \text { RUM } & \text { Remote Utility Module }\end{array}$




\section{REFERENCES}

1. T. W. Burgess et al., Design Guidelines for Remotely Maintained Equipment, ORNL/TM10864, Oak Ridge National Laboratory, Oak Ridge, Tennessee 1988.

2. D. R. Doman (ed.), Design Guides for Radioactive Material Handling Facilities and Equipment, American Nuclear Society, La Grange Park, Illinois, 1988.

3. J. Garin and M. J. Rennich, Remote Maintenance Design Guide for Advanced Fuel Reprocessing Facilities, ORNL/CFRP-81/19, Oak Ridge National Laboratory, Oak Ridge, Tennessee, 1981.

4. A. D. Deutschman, W. J. Michels, and C. E. Wilson, Machine Design, Theory and Practice, Macmillan Publishing Co. Inc., New York, 1975.

5. M. B. Bruce and M. V. Davis, Radiation Effects on Organic Materials in Nuclear Plants, EPRI Report NP-2129, November 1981.

6. J. A. Harrell, P. L. Manke, and J. E. Gover, The Application of Remote Electronics in a Nuclear Fuel Reprocessing Environment: Radiation Effects and Design Guidelines, SAND82-2151, Sandia National Laboratories, January 1983.

7. K. U. Vandergriff and S. Kawatsuma, An Assessment of the Impact of Radiation on Proposed RETF Components, ORNL/CFRP-88/6, Oak Ridge National Laboratory, Oak Ridge, Tennessee, June 1988.

8. K. U. Vandergriff, Designing Equipment for Use in Gamma Radiation Environments, ORNL/TM-11175, Oak Ridge National Laboratory, Oak Ridge, Tennessee, May 1990.

9. K. U. Vandergriff, Testing Components for Use in High-Level Gamma Radiation Environments, ORNL/TM-11507, Oak Ridge National Laboratory, Oak Ridge, Tennessee, May 1991.

6. D. E. Holcomb and B. L. Burks, A Review of the Environmental Survivability of Telerobotic Control Sensor Systems for Use in Nuclear Waste Tanks, ORNL/TM-12710, Oak Ridge National Laboratory, Oak Ridge, Tennessee, May 1994.

7. D. P. Kuban, M. W. Noakes, and E. C. Bradley, The Advanced Servomanipulator System: Development Status and Preliminary Test Results, Proceedings of the ANS Topical Meeting on Remote Systems and Robotics in Hostile Environments, Pasco, Washington, pp. 638-644, March 29 - April 2, 1987. 